\title{
Hepatocellular Carcinoma: Diagnosis, Treatment Algorithms, and Imaging Appearance after Transarterial Chemoembolization
}

\author{
Patrick Vande Lune ${ }^{1}$, Ahmed K. Abdel Aal ${ }^{2}$, Sergio Klimkowski ${ }^{3}$, Jessica G. Zarzour ${ }^{4}$ \\ and Andrew J. Gunn*2 \\ ${ }^{1}$ University of Alabama at Birmingham School of Medicine, Birmingham, AL, USA; ${ }^{2}$ Division of Vascular and Interventional \\ Radiology, Department of Radiology, University of Alabama at Birmingham, Birmingham, AL, USA; ${ }^{3}$ Department of Radiology, \\ University of Alabama at Birmingham, Birmingham, AL, USA; ${ }^{4}$ Division of Abdominal Imaging, Department of Radiology, \\ University of Alabama at Birmingham, Birmingham, AL, USA
}

\begin{abstract}
Hepatocellular carcinoma (HCC) is a common cause of cancerrelated death, with incidence increasing worldwide. Unfortunately, the overall prognosis for patients with HCC is poor and many patients present with advanced stages of disease that preclude curative therapies. Diagnostic and interventional radiologists play a key role in the management of patients with HCC. Diagnostic radiologists can use contrast-enhanced computed tomography (CT), magnetic resonance imaging, and ultrasound to diagnose and stage HCC, without the need for pathologic confirmation, by following established criteria. Once staged, the interventional radiologist can treat the appropriate patients with percutaneous ablation, transarterial chemoembolization, or radioembolization. Follow-up imaging after these liver-directed therapies for $\mathrm{HCC}$ can be characterized according
\end{abstract}

Keywords: Interventional radiology; Interventional oncology; Hepatocellular carcinoma; Response criteria; Transarterial chemoembolization; Diagnostic radiology.

Abbreviations: AASLD, American Association for the Study of Liver Diseases; ACR, American College of Radiology; ADC, apparent diffusion coefficient; AJCC, American Joint Committee on Cancer; BCLC, Barcelona Clinic Liver Cancer; BUN, blood urea nitrogen; $\mathrm{CBCT}$, cone beam computed tomography; CEUS, contrast-enhanced ultrasound; CLIP, Cancer of the Liver Italian Program; CR, complete response; CT, computed tomography; CTACE, conventional transarterial chemoembolization; CTP, computed tomography perfusion; DEB-TACE, drug-eluting bead transarterial chemoembolization; DECT, dual energy computed tomography; EASL, European Association for the Study of the Liver; FDA, Food and Drug Administration; FDG, fludeoxyglucose; HAP, hepatic arterial liver perfusion; HAPI, hepatic arterial perfusion index; HBV, hepatitis B virus; $\mathrm{HCC}$, hepatocellular carcinoma; HCV, hepatitis C virus; HKLC, Hong Kong liver cancer; HPP, hepatic portal perfusion; IUCC, International Union Against Cancer; LI-RADS, liver imaging reporting and data system; MELD, model for end-stage liver disease; mRECIST, modified Response Evaluation Criteria in Solid Tumors; MRI, magnetic resonance imaging; NASH, nonalcoholic steatohepatitis; OLT, orthotopic liver transplant; OPTN, Organ Procurement and Transplantation Network; OS, overall survival; PD, progressive disease; PEI, percutaneous ethanol injection; $\mathrm{PET}$, positron emission tomography; $\mathrm{PR}$, partial response; qADC, quantitative apparent diffusion coefficient; qEASL, quantitative European Association for the Study of the Liver; RECIST, Response Evaluation Criteria in Solid Tumors; RFA, radiofrequency ablation; SD, stable disease; TAE, bland transarterial embolization; TNM, tumor-node-metastasis; TTP, time-to-progression; VEGFR, vascular endothelial growth factor receptor; VRECIST, volumetric Response Evaluation Criteria in Solid Tumors; UCSF, University of California at San Francisco; UNOS, United Network for Organ Sharing; WHO, World Health Organization; ${ }^{90} \mathrm{Y}$, yttrium-90.

Received: 3 July 2017; Revised: 2 November 2017; Accepted: 2 December 2017 *Correspondence to: Andrew J. Gunn, Division of Vascular and Interventional Radiology, Department of Radiology, University of Alabama at Birmingham, 619 $19^{\text {th }}$ St S, NHB 623, Birmingham, AL 35249, USA. Tel: $+1-205-975-4850$, Fax: +1-205-975-5257, E-mail: agunn@uabmc.edu to various radiologic response criteria; although, enhancement-based criteria, such as European Association for the Study of the Liver and modified Response Evaluation Criteria in Solid Tumors, are more reflective of treatment effect in HCC. Newer imaging technologies like volumetric analysis, dualenergy $\mathrm{CT}$, cone beam $\mathrm{CT}$ and perfusion $\mathrm{CT}$ may provide additional benefits for patients with $\mathrm{HCC}$.

Citation of this article: Vande Lune $P$, Abdel Aal AK, Klimkowski S, Zarzour JG, Gunn AJ. Hepatocellular carcinoma: diagnosis, treatment algorithms, and imaging appearance after transarterial chemoembolization. J Clin Transl Hepatol 2018;6 (2):175-188. doi: 10.14218/JCTH.2017.00045.

\section{Introduction}

Hepatocellular carcinoma (HCC) is a common cause of cancerrelated death. ${ }^{1}$ It occurs most often in the setting of cirrhosis, usually related to chronic hepatitis $C$ virus (HCV) infection or chronic hepatitis B virus (HBV) infection. Prolonged alcohol use and nonalcoholic steatohepatitis (NASH) are also significant risk factors. ${ }^{1,2}$ During the past two decades, the incidence of HCC in the USA has more than doubled, due largely in part to increasing rates of HCV infection. ${ }^{1,3}$ However, it is likely that the incidence of $\mathrm{HCC}$ is actually underestimated, as active surveillance for HCC is underutilized. ${ }^{4}$ Globally, HCC is an even greater public health concern, as it is the third leading cause of cancer-related deaths worldwide. ${ }^{5}$ Most of this cancer burden $(85 \%)$ falls on developing countries, with the highest incidence in regions where HBV infection is endemic. ${ }^{1}$

Despite the numerous existing strategies to treat HCC, the 5 -year survival rate remains below $12 \% .{ }^{1}$ In developing nations, survival rates are as low as $5 \% .{ }^{5}$ Surgical resection, transplantation and ablation are potentially curative treatment options for HCC. ${ }^{6}$ Unfortunately, only a minority of patients are eligible for these treatments at the time of diagnosis. ${ }^{2,7}$ Instead, patients frequently present with symptoms of cancer and liver failure, unless their tumors are identified early by surveillance methods. ${ }^{8}$ For patients presenting with more advanced disease, several treatments have been developed to slow disease progression. These include many liver-directed therapies, such as bland transarterial embolization (TAE), conventional transarterial chemoembolization (CTACE), drug-eluting beads TACE (DEB-TACE) and yttrium-90 ( $\left.{ }^{90} \mathrm{Y}\right)$ 
radioembolization. 6,9,10 Systemic chemotherapy regimens, including the kinase-inhibitor sorafenib, are also available. Yet, at the time of writing, CTACE is the only of these liverdirected methods that have been demonstrated to convey a survival benefit in randomized controlled trials. ${ }^{11,12}$ As such, CTACE is currently the standard of care for patients meeting criteria for intermediate-stage HCC as defined by the BarceIona Clinic Liver Cancer (BCLC) guidelines. ${ }^{13}$

The ability to assess treatment response after TACE is critical for determining the efficacy of previous treatments and the need for retreatment. Imaging response to treatment also has the potential to improve patient selection and predict patient outcomes. ${ }^{14}$ However, traditional imaging criteria, such as the World Health Organization (WHO) and Response Evaluation Criteria in Solid Tumors (RECIST), focus on tumor size as a marker of treatment. ${ }^{15,16}$ This is problematic in HCC, as size-based criteria have been shown to be poor predictors of patient survival after cytostatic treatment methods, such as TACE. ${ }^{17}$ It is important for healthcare practitioners who treat patients with HCC to be familiar with these concepts. Therefore, the purpose of this article is to review current imaging strategies in the diagnosis, staging and follow-up after TACE for patients with HCC.

\section{Imaging in the diagnosis of HCC}

Unlike most malignancies, the diagnosis of HCC can be made on imaging alone, without the need for pathologic confirmation. ${ }^{18}$ This requires imaging centers to pay strict heed to the highest standards during imaging acquisition and for radiologists to follow defined protocols during image interpretation and reporting. The following section will provide guidance in these areas.

\section{Technical considerations in image acquisition}

Computed tomography (CT) examinations for HCC should be performed using a multidetector scanner, containing at least 8 detector rows with minimal section thickness of $5 \mathrm{~mm}$ and bolus tracking set to the descending thoracic aorta. Thinner sections are preferable, particularly if multiplanar reconstructions are obtained. A power injector should also be used to achieve at least a $3 \mathrm{~mL} / \mathrm{sec}$ rate with minimum of $300 \mathrm{mg}$ of iodine $/ \mathrm{mL}$ for a total dose of $1.5 \mathrm{~mL} / \mathrm{kg}$ body weight. Unenhanced, late arterial phase (defined as having the artery fully enhanced and the beginning of enhancement of the portal vein), portal venous phase (defined as having the portal vein enhanced, peak liver parenchymal enhancement, and the beginning of enhancement in the hepatic veins), and delayed phase (3-5 m postcontrast injection) images should be obtained. ${ }^{19}$

For magnetic resonance imaging (MRI), a multiphasic contrast-enhanced examination should be performed with a 1.5 $\mathrm{T}$ or greater magnetic field strength scanner using multichannel phased-array body coils. Power injectors should be used to inject gadolinium-based contrast at the rate of $2 \mathrm{~mL} / \mathrm{s}$ with bolus tracking. Like in multiphasic CT exams, images should be obtained in unenhanced, late arterial, portal venous and delayed phases. Requisite sequences include: precontrast T1-weighted, multiphase postcontrast T1-weighted, 3D fatsuppressed gradient echo, T2-weighted images with and without fat saturation, and T1-weighted images in-phase and in opposed-phase. Diffusion-weighted sequences are also typically performed using at least two b-values. ${ }^{20} \mathrm{~A}$ low b-value sequence (typically between $0-50 \mathrm{~s} / \mathrm{mm}^{2}$ ) is obtained, followed by a high b-value sequence (usually $>500 \mathrm{~s} / \mathrm{mm}^{2}$ ), and then an apparent diffusion coefficient (ADC) map is generated. Breath holding techniques should be employed to obtain quality images. ${ }^{19}$ The determination of contrast enhancement can be difficult for lesions with inherent high T1 signal; thus, the utilization of subtracted images (images where the precontrast T1 sequences are subtracted from the postcontrast T1 sequences) can be useful in these scenarios. ${ }^{21}$ Studies have shown superior sensitivity of MRI over CT in diagnosing HCC; therefore, MRI is the preferred modality in evaluating patients with chronic liver disease. ${ }^{22,23}$

A variety of gadolinium-based contrast agents are available for clinical use, and their utility in the diagnosis and posttherapeutic imaging of HCC are worth mentioning here. The majority of gadolinium-based contrast agents can be classified as extracellular agents which, similar to iodinated contrast media, are passively filtered through the kidneys prior to excretion. ${ }^{24}$ When the diagnostic criteria discussed below are followed, these agents are highly specific $(>95 \%)$ in diagnosing $\mathrm{HCC} .{ }^{24}$ On the other hand, hepatobiliary contrast agents distribute into the vascular and extravascular spaces during the arterial and portal venous phases, progress into a transitional phase where the agent moves into a predominantly intracellular position (lasting approximately 2-5 $\mathrm{m}$ after injection), and then move into the hepatocytes and bile ducts during the hepatobiliary phase. ${ }^{25}$ Utilizing hepatobiliary agents, HCC is expected to demonstrate arterial enhancement and portal venous washout. Hepatobiliary agents are sensitive for HCC (79-100\%) but have overall poor specificity (33$92 \%$ ) due to the background liver uptake in the transitional phase and other non-HCC lesions that can demonstrate hypointensity on hepatobiliary phase imaging. ${ }^{24,26}$ Moreover, the appearance of $\mathrm{HCC}$ at delayed phase imaging is dependent upon the degree of tumor infiltration and well-differentiated HCC may take up hepatobiliary agents, leading to misdiagnosis. ${ }^{27}$ In the setting of monitoring treatment response, MRI with an extracellular agent may be preferred to hepatobiliary agents, which are prone to more arterial phase motion artifacts due to transient tachypnea. ${ }^{25}$

\section{Imaging characteristics of HCC}

HCC is primarily supplied by the hepatic arterial system, and thus enhances during the arterial phase of CT (Fig. 1) and MRI (Fig. 2) examinations with high specificity. ${ }^{28,29}$ In contrast, the surrounding hepatic parenchyma shows little enhancement in this phase because it is primarily supplied by the portal venous system. During the portal venous phase of imaging, the background hepatic parenchyma typically demonstrates normal homogeneous enhancement, while HCC will appear relatively hypoattenuating due to lack of portal venous supply. However, it should be noted that the enhancement of the hepatic parenchyma can be altered in cirrhotic patients. HCC continues to be hypoattenuating on delayed $(3 \mathrm{~m}$ ) phases as well. This characteristic perfusion pattern of HCC relative to the normal hepatic parenchyma is called "washout".

Delayed phase imaging is more sensitive to the washout effect than the portal venous phase (Fig. 3)..$^{28-31}$ Another characteristic imaging finding of HCC is that of a peripheral enhancing rim around the lesion that is present on venous or delayed phase imaging, referred to as a 'pseudocapsule'. The detection of a pseudocapsule may not improve diagnostic accuracy beyond the afore-mentioned features for larger 


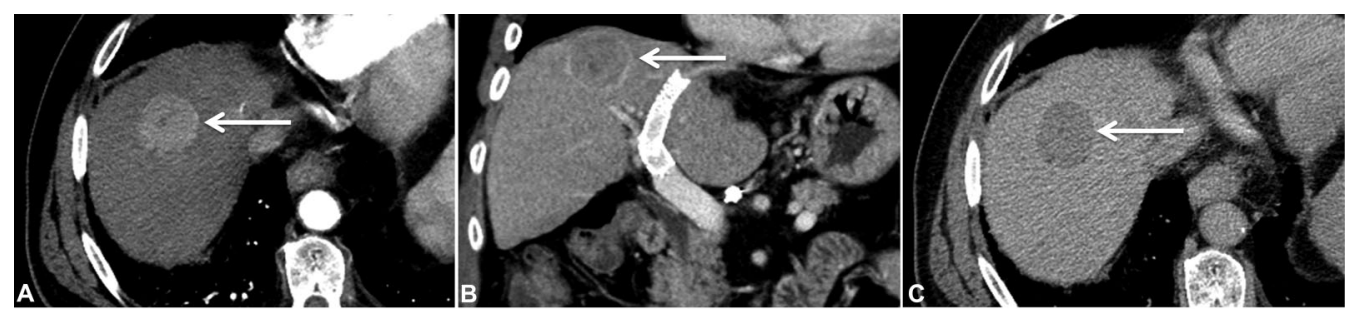

Fig. 1. Multiphase, contrast-enhanced CT scan in a 52 year-old man with a history of cirrhosis and transjugular intrahepatic portosystemic shunt placement. (A) axial CT image obtained in the arterial phase shows an avidly arterially-enhancing lesion near the hepatic dome (white arrow). (B) coronal CT image obtained in the portal venous phase shows washout within the lesion with surrounding pseudocapsule (white arrow). (C) axial CT image obtained in the 3-m delayed phase shows continued washout with the lesion (white arrow). This lesion was radiographically diagnostic of HCC.

lesions; yet, its recognition is critical to the classification of lesions between 1 and $2 \mathrm{~cm}$ in size. ${ }^{32}$ Arterial enhancement may be lacking in small, well-differentiated HCC as well as in infiltrative HCC. Subsequently, a high index of suspicion is required when evaluating cross-sectional imaging in a cirrhotic patient. Further, the presence of tumor invasion into the portal vein may cause an altered appearance on dynamic contrastenhanced CT or MRI with loss of typical HCC features, secondary to increased arterioportal shunting. ${ }^{33}$ Tumor thrombus within the affected portal vein may display the characteristic hyperenhancement and washout. ${ }^{34}$

The role of ultrasound in cirrhotic patients is primarily for screening. Conventional grayscale ultrasound has limited sensitivity and specificity for the diagnosis of HCC. ${ }^{32}$ HCC can have a variable appearance on ultrasound, but is most commonly hypoechoic. Any solid nodule detected by ultrasound should be considered as a potential HCC in a cirrhotic patient. Contrast-enhanced ultrasound (CEUS) can be extremely useful in patients with contraindications to receiving iodinated- or gadolinium-based contrast. CEUS was approved by the United States Food and Drug Administration (FDA) for the evaluation of focal liver lesions in 2016. It can be used safely in patients with chronic or acute renal failure. CEUS has been shown to have a sensitivity and specificity for HCC similar to CT and MRI. ${ }^{35}$ HCC will demonstrate arterial hyperenhancement with relative hypoenhancement to the normal liver parenchyma on later phase images (Fig. 4). ${ }^{36}$

\begin{abstract}
${ }^{18} \mathrm{~F}$-fludeoxyglucose (FDG) positron emission tomography (PET) has limited sensitivity for the detection of HCC and a high false-negative rate due to poor uptake in well-differentiated $\mathrm{HCC} .{ }^{3711} \mathrm{C}$-labeled acetate PET has been suggested as a means to increase sensitivity for the detection of primary HCC, with one study showing an increased sensitivity in detecting $\mathrm{HCC}$ when compared to FDG-PET. ${ }^{37}$ Disadvantages of ${ }^{11} \mathrm{C}$-acetate include the need for an on-site cyclotron and its short half-life $(20 \mathrm{~m})$.
\end{abstract}

\section{Categorization of HCC on imaging}

The categorization of HCC is not only important from a diagnostic standpoint but also from a resource allocation perspective. For example, the United Network for Organ Sharing (UNOS) is responsible for the administration of the Organ Procurement and Transplantation Network (OPTN), whose main goal is the fair allocation of transplant organs over the broadest possible geographic areas in order of decreasing medical urgency. ${ }^{38}$ In 2011, a new liver allocation policy was approved featuring an improved model for endstage liver disease (MELD) exception criteria that allows HCC patients to gain increased priority on liver transplant lists. This approach assigns liver transplantation priority to those with HCC since these patients have an increased risk of mortality due to tumor progression that pushes them outside of accepted transplantation criterion. In this new

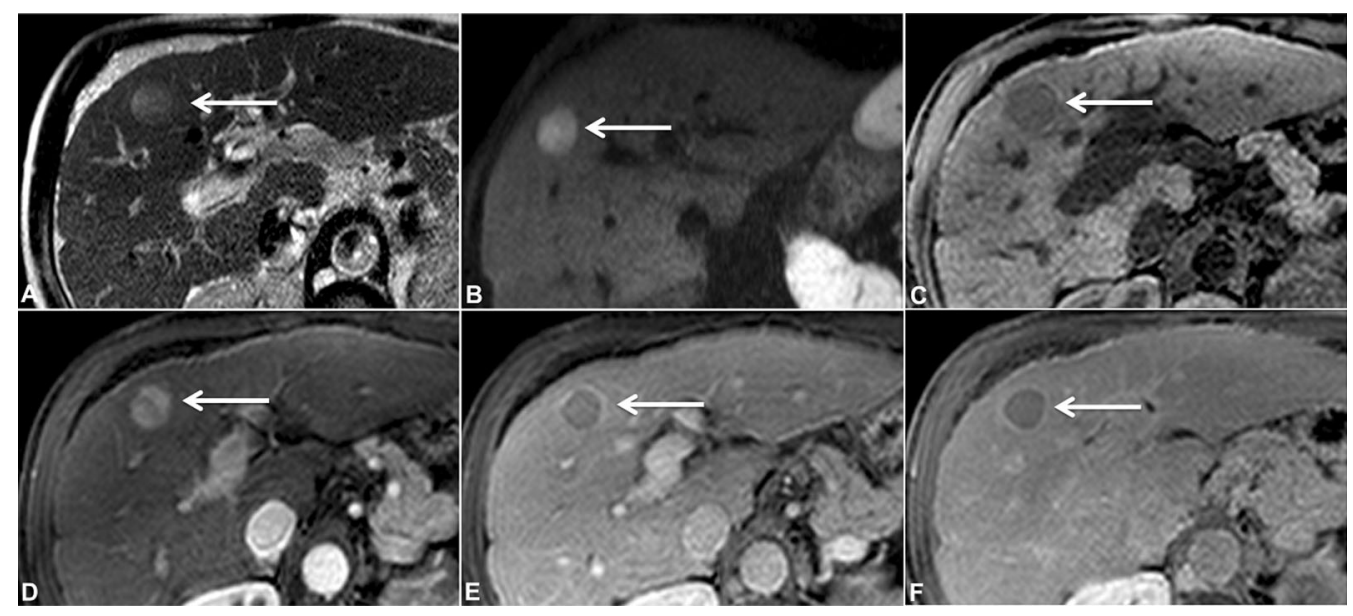

Fig. 2. Multiphase, contrast-enhanced MRI in a $\mathbf{6 4}$ year-old man with cirrhosis. The lesion (white arrows) shows characteristic findings of HCC, including increased T2 signal (A), restricted diffusion (B; obtained at a b-value of $700 \mathrm{~s} / \mathrm{mm}^{2}$ ), decreased signal on T1 precontrast image (C), arterial hyperenhancement (D), washout with pseudocapsule on venous phase (E), and washout with pseudocapsule on delayed 3-m phase (F). 


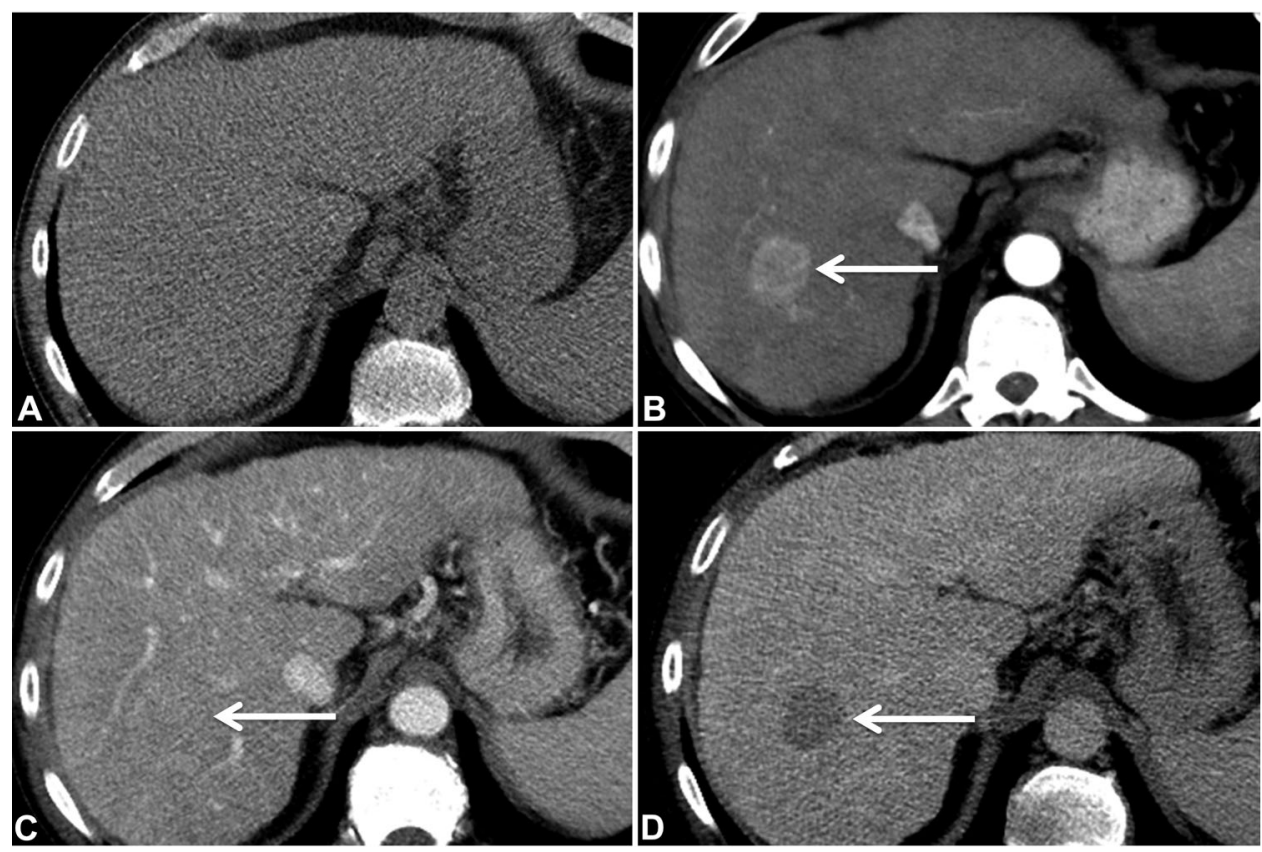

Fig. 3. Multiphase contrast-enhanced $\mathbf{C T}$ in a $\mathbf{5 5}$ year-old woman with cirrhosis. (A) the lesion in the right posterior hepatic lobe is not visualized on the unenhanced CT image. (B) axial CT image obtained in the arterial phase demonstrates an arterially-enhancing lesion (white arrow), raising concern for HCC. (C) the lesion become isoenhancing in the portal venous phase without clear washout (white arrow). (D) axial CT image in the 3-m delayed phase demonstrates clear washout and clinches the diagnosis of HCC. If the examination was terminated prior to obtaining the delayed phase, the diagnosis of HCC could not be made.

approach, MELD exception points are given to patients with T2 disease (defined as one tumor $\geq 2 \mathrm{~cm}$ and $\leq 5 \mathrm{~cm}$ or $2-3$ tumors $\geq 1 \mathrm{~cm}$ and $\leq 3 \mathrm{~cm}$ ) so long as they meet transplant criteria. These patients are then imaged with either CT or MRI every 2-3 months to ensure that they remain eligible for transplant. From this, it is clear that the ability of the radiologist to accurately diagnose and categorize HCC is paramount for patient care.

To aid the radiologist in this endeavor, there are established methods to categorize HCC. The most commonly employed and recognized system is that of the OPTN (Table 1). The OPTN system classifies liver lesions into OPTN class 0 through class 5 lesions. In this system, only an OPTN class 5 lesion can be called "diagnostic" of HCC. In this regard, a class $5 \mathrm{~A}$ lesion is $\geq 1 \mathrm{~cm}$ and $<2 \mathrm{~cm}$, demonstrates arterial hyperenhancement with washout, and contains a pseudocapsule. A patient must have 2 or 3 OPTN $5 A$ lesions to meet T2 criteria and qualify for
MELD exception points. An OPTN 5B lesion is $\geq 2 \mathrm{~cm}$ and $\leq 5 \mathrm{~cm}$ and has arterial hyperenhancement with either washout or a pseudocapsule. This qualifies for T2 disease and MELD exception points. ${ }^{39}$ Additional imaging features like lesion fat content, T2 hyperintense signal and diffusion restriction should be used carefully and at the discretion of the radiologist. At present, no automatic MELD points can be awarded to lesions in which these ancillary findings form the basis of an HCC diagnosis.

In 2011, the American College of Radiology (ACR) created the Liver Imaging Reporting and Data System (LI-RADS) to provide a standardized approach to the assessment of cirrhotic nodules and the diagnosis of HCC (Table 2). Even though the system is not universally adopted, radiologists should be familiar with its content. In this schema, LI-RADS 1 findings are definitely benign, LI-RADS 2-4 lesions have increasing probability of representing HCC, and LI-RADS 5 lesions are definitely
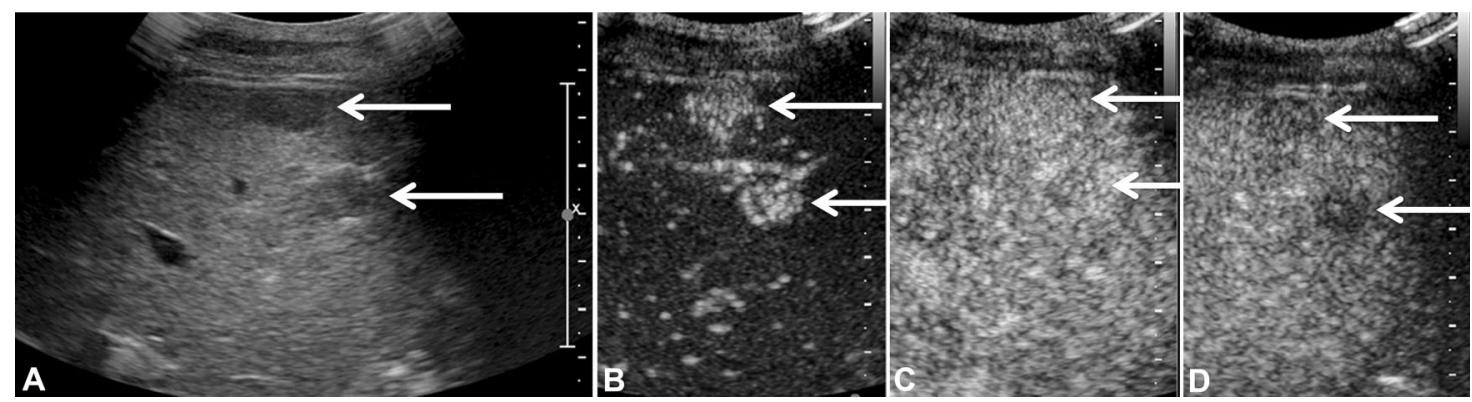

Fig. 4. Contrast-enhanced ultrasound in a $\mathbf{4 8}$ year-old man with cirrhosis. (A) gray scale image demonstrates two solid hypoechoic lesions in the left hepatic lobe (white arrows). (B) contrast-enhanced ultrasound image obtained in the arterial phase shows the lesions to have avid arterial enhancement. (C) venous phase image demonstrates the lesions becoming isoenhancing to the adjacent liver parenchyma. (D) delayed phase image obtained at 3-m shows washout within both of the lesions, consistent with HCC. 
Vande Lune P. et al: Imaging in hepatocellular carcinoma

Table 1. OPTN classification scheme for the categorization of HCC. Adapted from Wald C et al. ${ }^{39}$

\begin{tabular}{|c|c|}
\hline OPTN class; description & Comment \\
\hline $\begin{array}{l}0 \text {; incomplete or technically inadequate } \\
\text { exam }\end{array}$ & Repeat study \\
\hline 1 ; no evidence of $\mathrm{HCC}$ & Routine surveillance in appropriate population \\
\hline $\begin{array}{l}\text { 2; benign lesion or diffuse parenchymal } \\
\text { abnormality }\end{array}$ & Routine surveillance in appropriate population \\
\hline 3 ; indeterminate lesion & Follow-up imaging \\
\hline $\begin{array}{l}4 \text {; intermediate lesion - meets some criteria } \\
\text { for HCC but not diagnostic }\end{array}$ & Short term follow-up suggested +/- biopsy \\
\hline \multicolumn{2}{|l|}{$\begin{array}{l}\text { 5; meets diagnostic criteria for HCC, further } \\
\text { divided into subgroups }\end{array}$} \\
\hline $\begin{array}{l}5 \mathrm{~A} ; \geq 1 \mathrm{~cm} \text { and }<2 \mathrm{~cm} \text { on late arterial or } \\
\text { portal venous phase images }\end{array}$ & $\begin{array}{l}\text { Increased contrast enhancement in late hepatic arterial phase AND } \\
\text { washout during later phases of contrast enhancement AND peripheral rim } \\
\text { enhancement (capsule or pseudocapsule) }\end{array}$ \\
\hline $\begin{array}{l}5 A-g \text {; same size criteria as } 5 A \text { but lesion } \\
\text { grows in size }\end{array}$ & $\begin{array}{l}\text { Increased contrast enhancement in late hepatic arterial phase AND } \\
\text { maximum diameter increase by } 50 \% \text { or more documented on serial MRI or } \\
\text { CT obtained } \leq 6 \text { months apart - does not apply to ablated lesions }\end{array}$ \\
\hline \multirow[t]{4}{*}{$5 \mathrm{~B} ; \geq 2 \mathrm{~cm}$ and $\leq 5 \mathrm{~cm}$} & $\begin{array}{l}\text { Increased contrast enhancement in late hepatic arterial phase AND one of } \\
\text { the following: }\end{array}$ \\
\hline & 1. Washout during later contrast phases \\
\hline & 2. Late capsule or pseudocapsule enhancement \\
\hline & $\begin{array}{l}\text { 3. Growth by } 50 \% \text { or more documented on serial CT or MR images } \\
\text { obtained } \leq 6 \text { months apart - does not apply to ablated lesions } \\
\text { 4. Positive biopsy }\end{array}$ \\
\hline 5T; "treated" lesions & $\begin{array}{l}\text { Past liver-directed therapy for OPTN } 5 \text { HCC or biopsy-proven HCC with any } \\
\text { residual lesion }\end{array}$ \\
\hline $5 X ; \geq 5 \mathrm{~cm}$ & $\begin{array}{l}\text { Increased contrast enhancement in late hepatic arterial phase AND either } \\
\text { washout during later contrast phases OR capsule or pseudocapsule } \\
\text { enhancement }\end{array}$ \\
\hline
\end{tabular}

malignant. LI-RADS M refers to 'probable malignancy' that is not specific for HCC. ${ }^{25}$ Initially, LI-RADS was only applicable to CT and MRI. However, in 2016, the ACR incorporated CEUS into the LI-RADS system. ${ }^{40}$ Other benefits of LI-RADS include consideration of ancillary imaging findings, such as macrovascular invasion or pseudocapsule formation, and inclusion of advanced imaging techniques, such as diffusion-weighted imaging. ${ }^{25}$

\section{Staging and treatment for HCC}

The earliest attempt to stage patients with HCC was with the tumor-node-metastasis (TNM) classification, which has been clinically validated. ${ }^{41}$ This method is still the accepted staging system by the American Joint Committee on Cancer (AJCC) and International Union Against Cancer (UICC), and in one study has been demonstrated to be superior to some modern staging systems in terms of prognostic stratification and prediction. ${ }^{42,43}$ Its major drawback is that it does not account for the severity of underlying liver disease, which is an independent predictor of patient survival in HCC. ${ }^{31,44}$ As such, the Okuda staging system was developed, incorporating major indices of patient liver function. ${ }^{44,45}$ The Okuda classification, however, was limited by its inability to classify smaller tumors, when many patients were not diagnosed until more advanced stages of malignancy. ${ }^{44,46}$ The Cancer of the Liver Italian
Program (CLIP) system soon followed, seeking to overcome limitations of both the Okuda and TNM systems by accounting for liver function, tumor morphology, tumor extension in the liver, serum alpha fetoprotein levels and potential vascular invasion. ${ }^{47}$ It has been externally validated against the Okuda system in a randomized trial. ${ }^{48}$ However, one shortcoming of the CLIP system is that it does not include patient performance status, ${ }^{46}$ which is an independent predictor of survival. ${ }^{49}$

To better account for performance status, the BCLC staging system was published shortly after the CLIP system. ${ }^{50}$ The BCLC system includes an assessment of liver disease, tumor extension and presence of constitutional symptoms, in addition to offering treatment stratification for each disease stage. It has also demonstrated superior prognostic value when compared to numerous other staging systems. ${ }^{51,52}$ It has been endorsed by both the European Association for the Study of the Liver (EASL) and the American Association for the Study of Liver Diseases (AASLD). ${ }^{31,53}$ Another recent classification system of note is the Hong Kong Liver Cancer (HKLC) staging system. ${ }^{54}$ The major difference between HKLC and BCLC is that the HKLC system offers more aggressive treatment options. ${ }^{54}$ However, the HKLC system is limited when compared to the BCLC in that it investigated a cohort with primarily HBV-induced cirrhosis. ${ }^{55}$ Furthermore, the HKLC system has not been externally validated in non-Asian populations, whereas the BCLC system has been validated in numerous 
Vande Lune P. et al: Imaging in hepatocellular carcinoma

Table 2. Liver imaging reporting and data system (LI-RADS) for HCC. Adapted from the American College of Radiology. ${ }^{24,40}$

\begin{tabular}{|c|c|c|}
\hline LI-RADS class & Description & Comment \\
\hline 1 & Benign & $\begin{array}{l}\text { Cyst, hemangioma, perfusion alteration (e.g., arterioportal shunt), hepatic fat } \\
\text { deposition/sparing, hypertrophic pseudomass, confluent fibrosis or focal scar, etc. } \\
\text { OR } \\
\text { It disappears without treatment }\end{array}$ \\
\hline 2 & Probably benign & $\begin{array}{l}\text { Suggestive of a benign entity based on experience, as above } \\
\text { OR } \\
\text { Distinctive nodule without malignant features* } \\
\text { OR } \\
\text { Stable imaging features for } \geq 2 \text { years } \\
\text { OR } \\
\text { Probable disappearance in the absence of treatment }\end{array}$ \\
\hline 3 & $\begin{array}{l}\text { Intermediate } \\
\text { probability of } \\
\text { being benign }\end{array}$ & $\begin{array}{l}<2 \mathrm{~cm} \text { : } \\
\text { Mass-like configuration with arterial-phase hyperenhancement and no additional } \\
\text { major features } \\
\text { OR } \\
\text { Mass-like configuration with arterial phase hypoenhancement and } \leq 1 \text { additional } \\
\text { major feature } \\
\geq 2 \mathrm{~cm} \text { : } \\
\text { Mass-like configuration with arterial phase hypoenhancement and no additional } \\
\text { major features } \\
\text { Any size: } \\
\text { Non-mass-like configuration and neither LR-1 nor LR- } 2 \\
\text { OR } \\
\text { Cannot be categorized as LR-1, LR- } 2, \text { LR- } 4 \text {, or LR- } 5 \\
\text { OR } \\
\text { Meets criteria for LR- } 4 \text { or LR-5, with stability for } \geq 2 \text { years }\end{array}$ \\
\hline 4 & Probably HCC & $\begin{array}{l}\text { Category } A(<2 \mathrm{~cm}) \text { : } \\
\text { Mass-like configuration with arterial phase hyperenhancement and } 1 \text { additional } \\
\text { major feature } \\
\text { OR } \\
\text { Mass-like configuration with arterial phase iso- or hypoenhancement and } 2 \\
\text { additional major features } \\
\text { OR } \\
\text { Probable tumor within lumen of vein } \\
\text { Category B }(\geq 2 \mathrm{~cm}) \text { : } \\
\text { Mass-like configuration with arterial phase hyperenhancement and no additional } \\
\text { major features } \\
\text { OR } \\
\text { Mass-like configuration with arterial phase iso- or hypoenhancement and } 1 \text { or } 2 \\
\text { additional major features } \\
\text { OR } \\
\text { Probable tumor within lumen of vein }\end{array}$ \\
\hline 5 & $\mathrm{HCC}$ & $\begin{array}{l}\text { Category } A(\geq 1 \mathrm{~cm} \text { but }<2 \mathrm{~cm}) \text { : } \\
\text { Mass-like configuration with arterial phase hyperenhancement and } 2 \text { additional } \\
\text { major features } \\
\text { OR } \\
\text { Definite tumor within lumen of vein } \\
\text { Category } B(\geq 2 \mathrm{~cm}) \text { : } \\
\text { Mass-like configuration with arterial phase hyperenhancement and } 1 \text { or } 2 \\
\text { additional major features } \\
\text { OR } \\
\text { Definite tumor within lumen of vein }\end{array}$ \\
\hline
\end{tabular}

\footnotetext{
* Solid nodule <20 mm distinctive in imaging appearance compared to background nodules AND with no major feature of HCC, and no ancillary feature of malignancy

\# Additional major features; portal venous phase or later phase hypoenhancement, increase in diameter of at least $1 \mathrm{~cm}$ within 1 year

Abbreviations: HCC, hepatocellular carcinoma; LR, LI-RADS.
}

studies worldwide. ${ }^{49,56,57}$ While there is no universally accepted staging system per AASLD guidelines, ${ }^{31}$ the BCLC staging system is the most widely used and recognized. ${ }^{58,59}$ As such, it is emerging as the standard staging system in Western populations. The BCLC system will therefore be discussed in more detail below. 
BCLC stratifies patients into five groups, from stage 0 to stage $D$. Stage 0 (very early stage) has a single nodule $\leq 2 \mathrm{~cm}$ without tumor invasion into surrounding tissues, in asymptomatic patients with preserved liver function. Stage A (early disease) is characterized by a solitary HCC of any size, or 3 nodules $<3 \mathrm{~cm}$, in asymptomatic patients with Child-Pugh $A$ or $B$ classification. Per BCLC guidelines, stages 0 and $A$ can be treated with curative therapies, such as resection, orthotropic liver transplantation (OLT) and ablation. Resection and OLT result in the best outcomes for BCLC stage A HCC, with 60$80 \%$ of patients surviving for 5 years. ${ }^{8}$ The Milan criteria are an accepted guide to determine suitability for OLT. These require a patient to have either one lesion smaller than $5 \mathrm{~cm}$, or up to three lesions smaller than $3 \mathrm{~cm}$, and no extrahepatic manifestations or vascular invasion. ${ }^{60}$ A meta-analysis found that patients who met these specifications had better posttransplant survival rates than patients with larger tumor burdens. ${ }^{61}$ Transplantation eligibility guidelines from the University of California San Francisco Criteria (UCSF) are less restrictive and less widely used than the Milan criteria. The UCSF criteria are as follows: single lesion $\leq 6.5 \mathrm{~cm}$, or $2-3$ lesions of $\leq 4.5 \mathrm{~cm}$ with a total tumor diameter $\leq 8 \mathrm{~cm}$. ${ }^{62}$ Some centers reserve ablation for patients who are not operative candidates.

BCLC stage B (intermediate disease) consists of multinodular tumors, without macrovascular invasion or extrahepatic spread, in asymptomatic patients with intact liver function and performance status of 0 . Treatment of stage $B$ disease is aimed at palliation rather than cure. Stage $B$ patients may be treated with CTACE, the efficacy of which is supported by level I evidence. ${ }^{11-13,63}$ Absolute contraindications to TACE include decompensated cirrhosis, extensive tumor replacing both lobes of the liver, uncorrectable coagulopathy, renal insufficiency (creatinine clearance $<30 \mathrm{~mL} / \mathrm{m}$ ) and severely reduced portal venous flow. ${ }^{64}$ Relative contraindications to TACE include tumor size $>10 \mathrm{~cm}$, untreated biliary obstruction, untreated varices at high risk of bleeding, active cardiopulmonary dysfunction and an incompetent papilla. ${ }^{64}$ CTACE utilizes the transcatheter delivery of a high dose chemotherapeutic agent (usually doxorubicin) in an emulsion with ethiodized oil directly into the hepatic arterial supply of the tumor, followed by arterial embolization with particles to prevent washout. ${ }^{65}$ DEB-TACE involves the transcatheter delivery of chemotherapy-loaded microspheres into the hepatic arterial system supplying the tumor, thereby providing sustained drug delivery in combination with tumor ischemia (Fig. 5) ${ }^{65} \mathrm{~A}$ randomized phase II study comparing cTACE and DEB-TACE found that DEB-TACE was associated with a significant reduction in liver toxicity and drug-related adverse effects. ${ }^{66}$ TAE is another method that involves embolization of vessels supplying the tumor with polyvinyl alcohol particles and/or trisacryl microspheres, in the absence of chemotherapy. In combination with ablation, bland embolization achieves overall survival (OS) rates similar to surgical resection. ${ }^{67}$ TAE has also been demonstrated to be an effective method of salvage therapy for patients with recurrent HCC after surgical resection. ${ }^{68}$

Another potential option for palliation of stage $B$ disease is ${ }^{90} \mathrm{Y}$ radioembolization, which delivers high-dose $\beta$-emitting radiolabeled microspheres through a microcatheter to the tumor via its hepatic arterial supply. ${ }^{10,69}$ This technique is superior to external beam therapy in that it lessens the risk of radiation-induced liver disease. ${ }^{10}$ One advantage of radioembolization over TACE is that the spheres are smaller. Thus, they are not truly embolic to the hepatic arterial supply, which limits the risk of ischemic liver failure in patients with tumor extension into the portal vein. ${ }^{65,70} \mathrm{~A}$ phase 2 trial in patients with $\mathrm{HCC}$ with and without portal vein thrombosis showed a favorable tumor response rate with radioembolization in patients with portal vein thrombosis. ${ }^{70}$ Additionally, at least one randomized phase 2 study demonstrated significantly longer time to progression for patients treated with ${ }^{90} \mathrm{Y}$ when compared to those treated with cTACE. ${ }^{71}$

Patients with either macrovascular invasion or extrahepatic spread or a performance status of 1 or greater are classified as stage C (advanced-stage), for which the standard of care is sorafenib. ${ }^{38}$ Sorafenib acts by inhibiting multiple kinases, such as Raf-1, B-Raf and the receptor tyrosine kinase activity of vascular endothelial growth factor receptors (VEGFRs) 1, 2, and 3 . Sorafenib has been shown to convey survival benefit in patients with advanced HCC. ${ }^{72}$ However, early case series have shown that TACE can be safely performed for patients with advanced-stage disease. ${ }^{73}$ In the case of sorafenib failure or intolerance, another option is c-met inhibition, which has several clinical trials underway evaluating agents such as cabozatinib and tivantinib. ${ }^{60}$ Patients with cancer symptoms related to advanced liver failure, tumor growth with vascular involvement, extrahepatic spread or performance status $>2$ are classified as stage $D$ (end-stage). The standard of care for stage $D$ is best supportive care. ${ }^{50}$

\section{Evaluation of the imaging response after liver-directed} therapies

After delivery of a liver-directed therapy for HCC, it is crucial to accurately characterize the patient's response. Consequently, multiple radiologic criteria have been developed to assess tumor response and guide further therapy. The most commonly used criteria will be discussed below and are summarized in Fig. 6.

\section{WHO}

The advent of new cancer therapies necessitated a standard way in which to report treatment response. Subsequently, the WHO created consensus guidelines to allow accurate comparison of clinical trials. These guidelines delineate four categories of response to treatment: complete response (CR), partial response (PR), progressive disease (PD), and stable disease (SD). CR is defined as no measurable disease. PR is defined as a $50 \%$ decrease in the sum of the products of the bidimensional lesion diameters and no new disease. PD is defined as a $25 \%$ or more increase in size of any lesion or development of new lesions. SD is defined as neither progressive disease nor partial response (Figs. 6A and $6 \mathrm{~B}$ ). ${ }^{15}$ The WHO system is considered most useful with single lesions and with cytotoxic therapies. Drawbacks include no definition of minimal reportable tumor size, no recommendation on the number of lesions that are to be considered recordable, and inability to characterize lesional enhancement characteristics. Additionally, everyday use was complicated by variation in measurement methodology. Advances in CT and MRI led to more confusion about how to integrate these modalities into the existing system. ${ }^{16}$

\section{RECIST}

The problems with WHO criteria led to the development of RECIST. These guidelines provided direction regarding the timing of baseline imaging (e.g., to be done no more than 4 


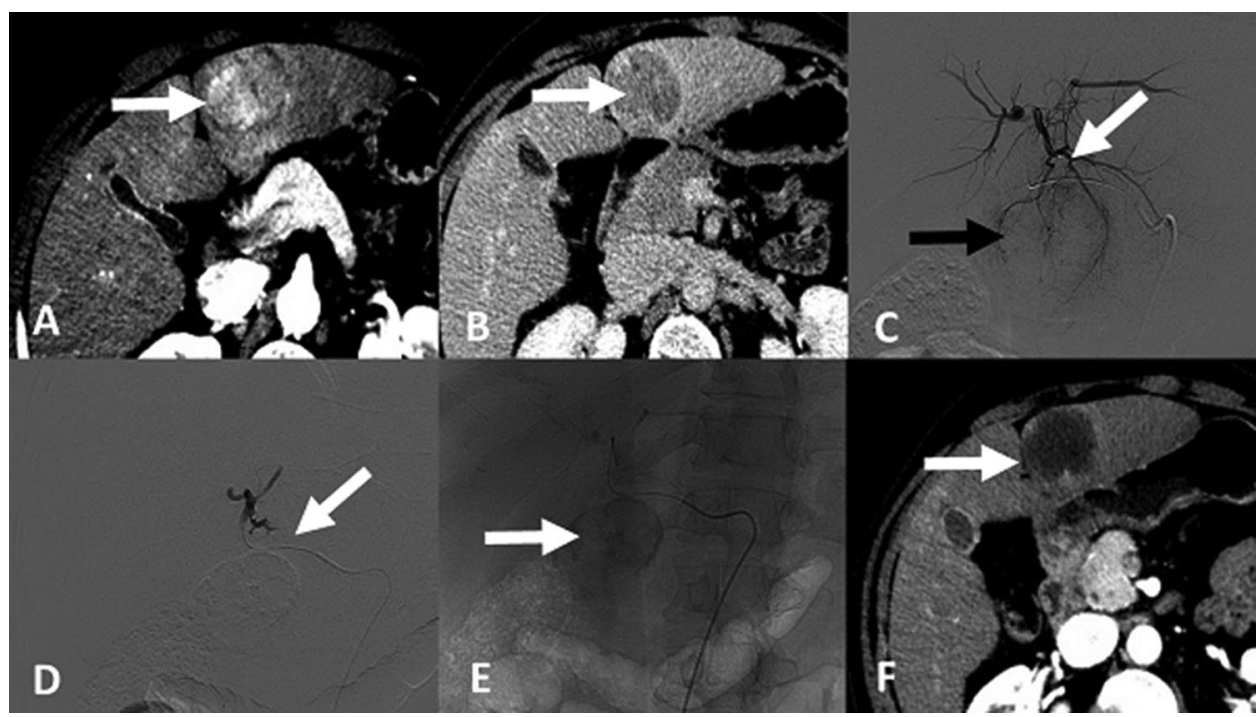

Fig. 5. 57 year-old man with cirrhosis. (A) contrast-enhanced axial CT scan in arterial phase shows a $4.8 \mathrm{~cm}$ arterially-enhancing lesion in segment III (white arrow). (B) contrast-enhanced axial CT scan in delayed phase shows the lesion to have characteristic washout and a pseudocapsule (white arrow), confirming the diagnosis of HCC (C) digital subtraction arteriogram (DSA) image during his DEB-TACE procedure with the microcatheter in the segment III artery (white arrow) shows tumor vascularity in segment III (black arrow). (D) DSA image after treatment by DEB-TACE shows the elimination of tumor vascularity (white arrow). (E) spot radiograph taken after delivering of chemotherapy-labeled beads demonstrates excellent contrast stain in the segment III lesion (white arrow). (F) contrast-enhanced axial CT scan in arterial phase obtained 1 month after DEB-TACE shows no enhancement in the segment III lesion, confirming a complete response to treatment.

weeks prior to the initiation of therapy) and the technique of follow-up imaging (e.g., use the same modality or technique that was used for baseline scans). RECIST introduces the concept of 'measurable disease' (e.g., $>1 \mathrm{~cm}$ in size on CT or MRI) and states that the largest and most reproducible lesions should be used as "target lesions" when evaluating response but that no more than five target lesions per organ or more than ten total target lesions from representative organs should be measured and reported. All other sites of disease should be identified as "non-target lesions" on baseline exam and only their presence, progression or absence should be reported on follow-up imaging. ${ }^{16}$
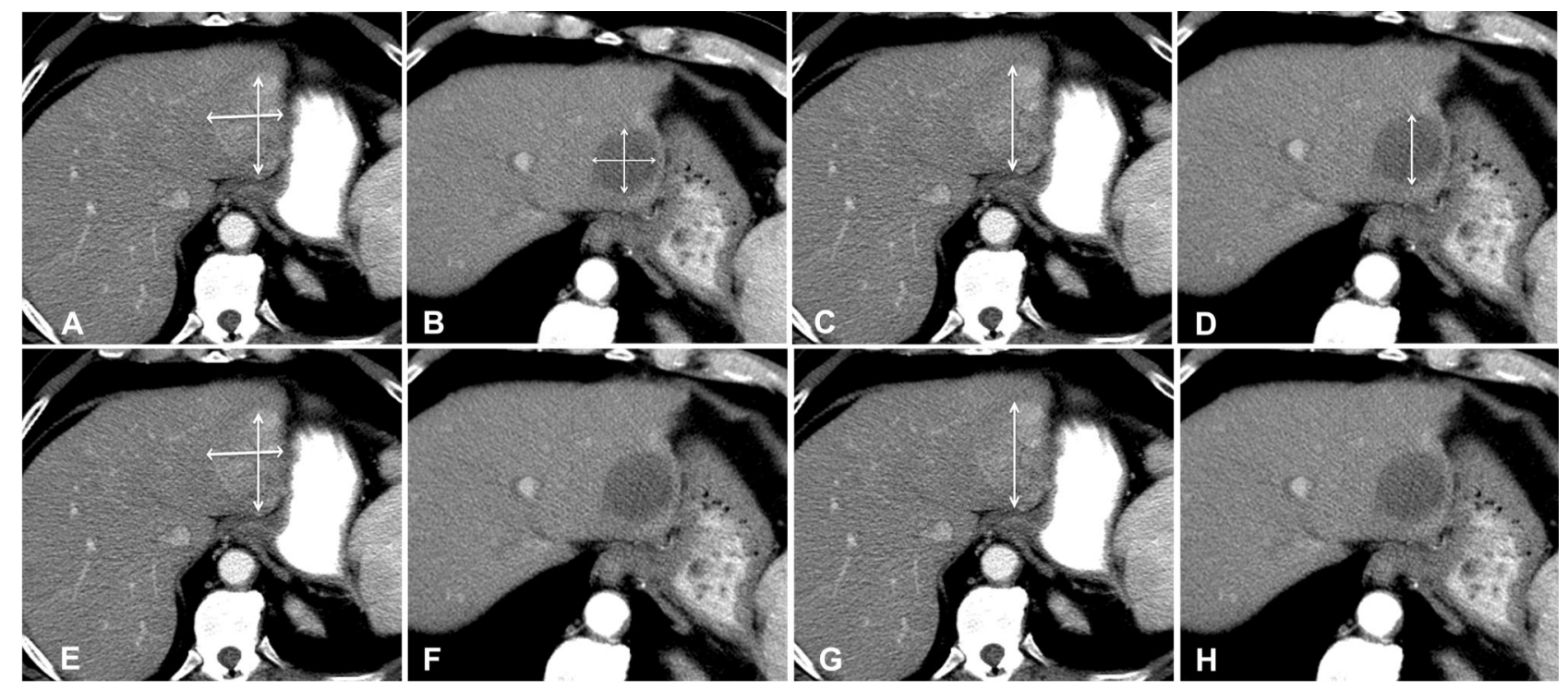

Fig. 6. Multiple axial CT images in arterial phase in a 71 year-old man with HCC who was treated by DEB-TACE that demonstrate the most commonly employed radiologic response criteria. (A) product of the bidimensional measurements of the $\mathrm{HCC}$ on CT prior to DEB-TACE is $4.2 \mathrm{~cm} \times 2.7 \mathrm{~cm}=11.34$. (B) product of the bidimensional measurements of the HCC on CT 1 month after DEB-TACE is $2.7 \mathrm{~cm} \times 2.6 \mathrm{~cm}=7.02$. This lesion is thus classified as stable disease by WHO criteria because it did not achieve a $>50 \%$ reduction in size. (C) per RECIST criteria, the longest unidimensional measurement of the HCC on CT prior to TACE is recorded (4.2 $\mathrm{cm}$ ). (D) on follow-up imaging, the longest unidimensional measurement is $2.7 \mathrm{~cm}$, a $>30 \%$ decrease in size. This is a partial response by RECIST criteria. (E) product of the bidimensional measurement of the enhancing portion of the HCC on CT prior to DEB-TACE is $4.2 \mathrm{~cm} \times 2.7 \mathrm{~cm}=11.34$. (F) follow-up imaging demonstrates no residual arterial, a complete response by EASL criteria. (G) per mRECIST criteria, the longest unidimensional measurement of the enhancing portion of the HCC on CT prior to TACE is recorded $(4.2 \mathrm{~cm})$. (H) follow-up imaging demonstrates no residual arterial enhancement, a complete response by mRECIST criteria. 
Like WHO, RECIST is a sized-based response criteria where the sum of the longest unidimensional diameters from all target lesions are measured (Figs. 6C and 6D). In RECIST, $\mathrm{CR}$ is defined as disappearance of all target lesions, PR is defined as a $30 \%$ decrease in the sum of the unidimensional diameters of all target lesions, PD is defined as a $20 \%$ increase in the sum of the unidimensional diameters of all target lesions or the development of any new lesions, and SD is defined as insufficient diameter increase to qualify as PD nor sufficient decrease in diameter to qualify as partial response. RECIST also defines nonmeasurable lesions that include bone lesions, leptomeningeal disease, ascites, pleural/pericardial effusions, inflammatory breast disease, lymphangitis, cystic lesions and abdominal masses that are not confirmed or followed by imaging.

In 2009, RECIST was updated to improve overall usability. RECIST 1.1 changed the number of reportable target lesions per organ from five to two and the total number of target lesions from ten to five. Lymph nodes were allowed to be used as target lesions. ${ }^{74}$ RECIST 1.1 requires an absolute minimum lesion size increase of $>5 \mathrm{~mm}$ to preclude overcalling PD when a target lesion is small. The update also includes recommendations on optimal anatomic assessment and PET imaging. The drawbacks of RECIST and RECIST 1.1, like their WHO predecessor, lie in their inability to account for lesion enhancement characteristics. Other poorly addressed tumor response considerations include irregular, confluent or circumferential tumor morphology, asymmetric size changes, and differential lesion response. Moreover, neither WHO nor RECIST guidelines consider new technologies such as multiplanar imaging or volumetric tumor analysis.

\section{EASL}

Historically, WHO and RECIST guidelines have been employed in clinical trials, utilizing tumor size as the primary surrogate for treatment response. ${ }^{13,75}$ Nevertheless, there are limitations to consider when evaluating tumor response based solely on its size. For example, size-based criteria do not take into account the immediate posttherapeutic biologic and metabolic changes in the tumor that affect its viability and influence treatment efficacy. ${ }^{74}$ Therefore, relying on size alone could have the unintended consequence of misclassifying some therapies as ineffective or suboptimal. This is particularly true for liver-directed therapies such as TACE, which are cytostatic rather than cytotoxic. ${ }^{17,72,76}$ For example, one study with a cohort of 55 patients who underwent liver-directed therapy for HCC found that RECIST missed all cases of CR and underestimated PR due to tissue necrosis. ${ }^{74}$ With this in mind, EASL released tumor response criteria in 2000 that included lesion enhancement characteristics and bidirectional measurements (Figs. 6E and 6F).

EASL definitions of $C R, P R, P D$ and $S D$ are consistent with those of the WHO. The key difference is that the EASL system also takes into account enhancement characteristics to distinguish viable tumor from tumor necrosis. ${ }^{53}$ Viable tumor is defined as CT or MRI arterial phase enhancement. Careful evaluation of the unenhanced images must be taken into account because retained ethiodized oil within the HCC after CTACE may obscure arterial enhancement on CT. This problem is mitigated when MRI is used as it is not subject to obscuration of arterial enhancement from ethiodized oil. Despite the improvement with these guidelines, EASL suffers from similar problems as the WHO system; namely, it provides no definition for concepts such as measureable lesions, target versus non-target lesions, or how to report lymphadenopathy.

\section{Modified (m)RECIST}

In 2009, the AASLD and the National Cancer Institute adopted the mRECIST guidelines for use in clinical trials for patients with HCC. ${ }^{77}$ Like the EASL guidelines, mRECIST is focused on the presence of arterial enhancement within the lesion as a surrogate for viable tumor rather than relying primarily on the lesion's overall size. mRECIST definitions of CR, PR, PD and SD are consistent with those of RECIST, with the caveat that the unidimensional measurement of any viable tumor on late arterial phase images should not include any intervening areas of tissue necrosis (Figs. 6G and 6F). Similarly, the definitions of measureable lesions, target lesions and nontarget lesions were unchanged from RECIST. However, mRECIST did address the fact that some lesions, such as infiltrative-type $\mathrm{HCC}, \mathrm{HCC}$ with poor border demarcation and $\mathrm{HCC}$ with atypical enhancement patterns, may be difficult to reliably measure and should, therefore, not be used as target lesions. Special considerations in mRECIST include classification of portal vein thrombosis as a nontarget lesion and consideration of porta hepatis lymphadenopathy as malignant if short axis diameter equals or exceeds $2 \mathrm{~cm}$.

\section{Imaging response to liver-directed therapies as a predictor of patient survival}

The primary goal of treating patients with HCC is to improve objective measures, such as OS and time-to-progression (TTP), while limiting toxicities and complications from treatment. This necessitates a multidisciplinary approach to patient selection and clinical follow-up after therapy to best identify those who will benefit from continued interventions. While imaging provides an invaluable data point in these decisions, other considerations, including laboratory values and physical performance, should also be part of the discussion. Regardless, the imaging appearance of the lesion after liver-directed therapies is often the driving force of whether or not a patient will be re-treated. This begs the important question of whether posttherapeutic imaging can be used as a reliable predictor of patient outcomes. The following section will outline some of the investigations performed on this topic.

Sala et al. ${ }^{14}$ retrospectively analyzed the data of 282 consecutive patients who underwent either percutaneous ethanol injection (PEI) $(n=203)$, radiofrequency ablation (RFA) $(n=$ 49 ) or combined TAE with PEI $(n=30)$ as therapy for HCC to determine what, if any, clinical parameters could be used as an independent predictor of patient survival. In this cohort, 197 patients were Child-Pugh A, while 85 were Child-Pugh B. Twenty-four clinical parameters were evaluated as potential predictors of survival and only initial CR to treatment ( $p=$ $0.02)$ and blood urea nitrogen (BUN) $(p=0.027)$ were independent predictors of survival for patients with Child-Pugh $A$ liver disease. For patients with Child-Pugh B liver disease, only initial CR to treatment $(p=0.014)$ was an independent predictor of patient survival. More recently, Shim et al. ${ }^{78}$ performed a retrospective analysis focused on determining which of the commonly employed radiologic response criteria were best at predicting patient outcomes after TACE. In this analysis, the authors selected patients with intermediate stage (BCLC B) HCC and Child-Pugh A liver disease to control for 
tumor burden and liver function, respectively. Each of the 332 patients were treated with CTACE and follow-up imaging for each patient was analyzed using WHO, RECIST, EASL and mRECIST criteria. The authors found that patients with a CR by enhancement-based criteria (EASL or MRECIST) survived longer than those who had any other type of response. Further, an imaging response by $\operatorname{EASL}(p<0.001)$ and mRECIST $(p<0.001)$ was found to be an independent predictor of survival. These findings were not true for the sizebased criteria of WHO and RECIST.

Similar to this study, Kim et al. ${ }^{79}$ also did a large retrospective analysis of 314 patients with HCC to evaluate whether any clinical factors could predict patient outcomes. The authors of this study only included patients with intermediate stage (BCLC B) HCC and Child-Pugh A liver disease to limit confounding variables. All patients were treated with cTACE and followed with contrast-enhanced imaging at regular intervals. Responses were only evaluated by mRECIST criteria. Multivariate analysis of this cohort found that both an initial response by mRECIST criteria ( $p<0.001$; defined as the response on the first followup scan) and a best response by mRECIST ( $p<0.001$; defined as response after on-demand retreatment when necessary) were independent predictors of OS, in addition to tumor size $(p=0.025)$ and number $(p<0.001)$. The results of these studies suggest that the enhancement-based criteria are potent predictors of patient outcomes after liver-directed therapies for those with early or intermediate stage HCC.

The efficacy of imaging response criteria for predicting survival for patients with advanced stage HCC is less clear. For example, Prajapati et al. ${ }^{80}$ performed a retrospective analysis of 120 patients who were treated with DEB-TACE to evaluate which radiologic response criteria could best predict patient survival. Patients with advanced stage liver disease (Child-Pugh C; $n=8$ ) and advanced/end-stage HCC (BCLC C and $\mathrm{D} ; n=86$ ) were included. A multivariate analysis of this cohort showed that a response by MRECIST criteria was the only independent predictor of survival $(p=0.013)$, although EASL approached statistical significance $(p=0.064)$. Neither WHO $(p=0.22)$ nor RECIST1.1 $(p=0.92)$ were able to predict patient survival in this study. Yet, Jung et al. ${ }^{81}$ also included patients with advanced stage (BCLC C), but not end-stage, HCC $(n=23)$ in their retrospective analysis of 98 patients treated with CTACE. All patients had either Child-Pugh A ( $n=$ $77)$ or Child-Pugh $\mathrm{B}(n=21)$ liver disease. Patients were imaged by either contrast-enhanced CT or MRI in order to assess treatment response. The authors demonstrated that an imaging response as defined by $\operatorname{EASL}(p<0.001)$ or $\operatorname{mRECIST}(p<0.001)$ was an independent predictor of survival by multivariate analysis, in addition to BCLC stage and a baseline alpha fetoprotein of $>200 \mathrm{ng} / \mathrm{mL}$.

However, Gunn et al. ${ }^{82}$ performed a retrospective review in 2017 to evaluate the ability of the various radiologic response criteria to predict outcomes after DEB-TACE for patients with advanced-stage (BCLC C) HCC. This analysis excluded patients with both earlier and later stages of HCC. All patients $(n=75)$ had either Child-Pugh A $(n=47)$ or Child-Pugh B $(n=28)$ liver disease and were followed at regular intervals postDEB-TACE by either contrast-enhanced CT or MRI. Unlike the above-mentioned studies, the authors found that neither WHO, RECIST, EASL or mRECIST were accurate predictors of OS or TTP. This finding raises the question of the value of the radiologic response criteria in this specific set of patients. For example, many of these patients will have extrahepatic disease or main portal vein invasion, which could affect their OS, but are not sufficiently treated when patients are receiving liver-directed therapies as their sole treatment for HCC. Certainly, larger studies are needed to verify these findings.

\section{Future directions in imaging for HCC}

Progress in technology and characterization of HCC has allowed a radiologic diagnosis to supplant the requirement of a tissue specimen prior to therapy. Despite these advances, there continues to be significant interest in ways to improve the diagnostic capabilities of imaging in HCC and some of these are discussed in brief below.

\section{Volumetrics}

Volumetric tumor assessment is a relatively new method of assessing response. ${ }^{83,84}$ In a study that included 122 patients with HCC, quantitative 3D analysis was performed of the dominant tumor to calculate enhancing tumor volume and was compared to tumor diameter in assessment of treatment response. ${ }^{85}$ Tumor volume was found to be a better predictor of survival than measurement of tumor diameter. Methods have been described to measure tumor volume and enhancement pattern on a voxel-by-voxel basis utilizing a semi-automatic tumor segmentation. ${ }^{86,87}$ HCC tumor volumes, enhancement of the entire tumor volume and percentage of enhancing tumor volume are used to determine a quantitative EASL (qEASL) and volumetric RECIST (vRECIST). ${ }^{79}$ Volumetric measurements have been shown to be more predictive of survival, better predictors of tumor size changes, and more reproducible than traditional imaging. ${ }^{8-89}$ Apart from enhancement, quantitative assessment of diffusion-weighted MRI has also been used to predict response as a measure of tumor necrosis, referred to as quantitative apparent diffusion coefficient (qADC) ${ }^{87} 3 \mathrm{D}$ volumetric analysis continues to be a priority in ongoing research. Presently, mRECIST does not directly employ tumor volume in assessment of tumor response. However, direct volumetric measurements should be priority in future clinical trials.

\section{Dual-energy (DE)CT}

DECT is used to visualize and quantify iodine-related density differences in tissue. ${ }^{89,90}$ This is significant in HCC as retained ethiodized oil after cTACE can make it difficult to detect contrast enhancement inside a viable tumor. Moreover, it has been shown that iodine concentration as measured with DECT can be used as surrogate marker for perfusion. ${ }^{91}$ Therefore, DECT is a promising method for assessing the efficacy of liverdirected therapies utilized in the treatment of patients with HCC. For example, one small prospective study evaluated the ability of DECT to categorize response to ${ }^{90} \mathrm{Y}$ radioembolization in 40 patients with HCC. ${ }^{92}$ The authors found that DECT classified more patients as SD and PR from the PD and SD categorizations, respectively, of the more established AASLD and Choi criteria. The authors attributed this change in categorization to the ability of DECT to identify contrast-enhancement compared to traditional multiphase CT. Another small study found that iodine uptake in HCC measured on DECT evaluated disease control in a manner consistent with AASLD; although, this study was based on 15 patients treated with sorafenib rather than locoregional therapy. ${ }^{89}$ 


\section{Cone beam (CB)CT}

The role of cone beam CT (СВCT) for the intraprocedural detection of HCC and assistance in vessel navigation during TACE or radioembolization is relatively is well-established. ${ }^{93-96}$ Yet, the question remains whether СBCT can be utilized for more than the facilitation of treatment. For example, the intratumoral deposition of ethiodized oil within HCC during CTACE is correlated to tumor necrosis and inversely related to local tumor recurrence. ${ }^{97,98}$ Additionally, CBCT has been shown to be as accurate as traditional multidetector $\mathrm{CT}^{99}$ and more accurate than fluoroscopy ${ }^{100}$ in its ability to detect ethiodized oil in HCC after CTACE. Therefore, CBCT could potentially be used intraprocedurally to quantify the amount of treatment deposited within the tumor and be used as a surrogate for treatment adequacy and response. Such a use may have the benefit of reducing the delay between treatment and assessment of treatment response, influencing intraprocedural treatment decisions. This is supported by at least one study in which the authors examined the ability of intraprocedural CBCT to accurately predict treatment response in 29 patients with HCC treated by DEB-TACE, in comparison to multiphase MRIs obtained at 1 month after therapy. ${ }^{101}$ In this study, CBCT was effective in predicting tumor response on follow-up MRIs according to EASL criteria.

An additional benefit of CBCT is that software advances have enabled quantitative perfusion measurements, such as parenchymal blood volume and dual-phase CBCT, which may represent new means to assess tumor response to treatment. Muller et al. ${ }^{102}$ attempted to assess the effectiveness of quantitative perfusion measurements at predicting response to TACE in HCC. In this analysis of 59 tumors in 43 patients treated with either CTACE or DEB-TACE, the authors concluded that computational features extracted from $\mathrm{CBCT}$, such as mean enhancement, washout ratio and 3D tumor enhancement volume, were overall poor prognosticators of HCC response to TACE. An important limitation of this approach is interinstitutional variability in CBCT software and the difficulties associated with obtaining proprietary software.

\section{Perfusion}

CT perfusion (CTP) is an intriguing modality for patients with $\mathrm{HCC}$ because treatment response is often related to the early changes in perfusion that occur with embolic locoregional therapies, such as TACE. ${ }^{103,104}$ CTP is analyzed using software packages that can produce a variety of parameters, such as blood flow, blood volume, hepatic arterial liver perfusion (HAP), hepatic portal perfusion (HPP) and hepatic arterial perfusion index (HAPI). Su et al. ${ }^{105}$ found that HAP, HAPI and HPP values may be useful predictors of treatment response to TACE. Tamandl et al. ${ }^{106}$ conducted a prospective study investigating whether CTP performed at 1 day postTACE could predict early response to TACE for HCC when compared to assessment with 6-week imaging using mRECIST criteria. The study enrolled 16 patients, with median follow-up of 19 months, and found that CTP could detect CR and PR within 1 day of treatment. Others have proposed utilizing pretreatment CTP to predict response to locoregional therapies. Reiner et al. ${ }^{107}$ performed a retrospective study of 16 patients who underwent radioembolization for HCC. HAP values were analyzed on pretreatment CTP images and then voxel-by-voxel histograms of the HAP values for each lesion were created and results were compared to findings on posttreatment imaging using mRECIST criteria. The study determined that mean HAP values of target lesions did not show significant differences between responders and nonresponders. It also showed that the coefficient of variation for histogram analysis of the lesions, a metric that represents tumor heterogeneity, was not significantly different between responders and nonresponders. The study did demonstrate, however, that tumors with higher HAP values for the $75^{\text {th }}$ and $50^{\text {th }}$ percentiles (representing increased vascularization) were significantly higher in responders.

\section{Conclusions}

The incidence of HCC is growing worldwide. A radiologic diagnosis of HCC is considered definitive as long as established criteria are followed. Patients have a variety of treatment options depending on their stage of disease. Enhancementbased radiologic response criteria, such as EASL and mRECIST, are key in assessing treatment response and predicting patient survival even though many emerging imaging technologies have shown promise in HCC.

\section{Conflict of interest}

The authors have no conflict of interests related to this publication.

\section{Author contributions}

Contributed to literature search, writing the primary draft $(P V L)$, editing and manuscript review (AKAA), literature search, writing the primary draft (SK), image acquisition and design, concept design, editing and manuscript review (JGZ), concept design, supervision, editing and writing of final draft (AJG).

\section{References}

[1] El-Serag HB. Hepatocellular carcinoma. N Engl J Med 2011;365:11181127. doi: 10.1056/NEJMra1001683.

[2] Singal AG, El-Serag HB. Hepatocellular carcinoma from epidemiology to prevention: translating knowledge into practice. Clin Gastroenterol Hepatol 2015;13:2140-2151. doi: 10.1016/j.cgh.2015.08.014.

[3] El-Serag HB, Davila JA, Petersen NJ, McGlynn KA. The continuing increase in the incidence of hepatocellular carcinoma in the United States: an update. Ann Intern Med 2003;139:817-823. doi: 10.7326/0003-4819-139-10200311180-00009.

[4] Hernaez R, El-Serag HB. Hepatocellular carcinoma surveillance: The road ahead. Hepatology 2017;65:771-773. doi: 10.1002/hep.28983.

[5] Bosetti C, Turati F, La Vecchia C. Hepatocellular carcinoma epidemiology. Best Pract Res Clin Gastroenterol 2014;28:753-770. doi: 10.1016/j.bpg. 2014.08.007.

[6] Forner A, Llovet JM, Bruix J. Hepatocellular carcinoma. Lancet 2012;379: 1245-1255. doi: 10.1016/S0140-6736(11)61347-0.

[7] Njei B, Rotman Y, Ditah I, Lim JK. Emerging trends in hepatocellular carcinoma incidence and mortality. Hepatology 2015;61:191-199. doi: 10. 1002/hep. 27388.

[8] Bruix J, Reig M, Sherman M. Evidence-based diagnosis, staging, and treatment of patients with hepatocellular carcinoma. Gastroenterology 2016; 150:835-853. doi: 10.1053/j.gastro.2015.12.041.

[9] Pesapane F, Nezami N, Patella F, Geschwind JF. New concepts in embolotherapy of HCC. Med Oncol 2017;34:58. doi: 10.1007/s12032-017-0917-2.

[10] Molvar C, Lewandowski RJ. Intra-arterial therapies for liver masses: data distilled. Radiol Clin North Am 2015;53:973-984. doi: 10.1016/j.rcl.2015. 05.011.

[11] Llovet JM, Real MI, Montaña X, Planas R, Coll S, Aponte J, et al. Arterial embolisation or chemoembolisation versus symptomatic treatment in patients with unresectable hepatocellular carcinoma: a randomised controlled trial. Lancet 2002;359:1734-1739. doi: 10.1016/S0140-6736(02)08649-X. 
[12] Cammà C, Schepis F, Orlando A, Albanese M, Shahied L, Trevisani F, et al. Transarterial chemoembolization for unresectable hepatocellular carcinoma: meta-analysis of randomized controlled trials. Radiology 2002; 224:47-54. doi: 10.1148/radiol.2241011262.

[13] EASL-EORTC clinical practice guidelines: management of hepatocellular carcinoma. J Hepatol 2012;56:908-943. doi: 10.1016/j.jhep.2011.12.001.

[14] Sala M, Llovet JM, Vilana R, Bianchi L, Solé M, Ayuso C, et al. Initial response to percutaneous ablation predicts survival in patients with hepatocellular carcinoma. Hepatology 2004;40:1352-1360. doi: 10.1002/hep.20465

[15] Miller AB, Hoogstraten B, Staquet M, Winkler A. Reporting results of cancer treatment. Cancer 1981;47:207-214. doi: 10.1002/1097-0142(19810101) 47:1<207: :AID-CNCR2820470134>3.0.CO;2-6.

[16] Therasse P, Arbuck SG, Eisenhauer EA, Wanders J, Kaplan RS, Rubinstein L, et al. New guidelines to evaluate the response to treatment in solid tumors. European Organization for Research and Treatment of Cancer, National Cancer Institute of the United States, National Cancer Institute of Canada. J Natl Cancer Inst 2000;92:205-216. doi: 10.1093/jnci/92.3.205.

[17] Shepherd FA, Rodrigues Pereira J, Ciuleanu T, Tan EH, Hirsh V, Thongprasert $\mathrm{S}$, et al. Erlotinib in previously treated non-small-cell lung cancer. $\mathrm{N}$ Engl J Med 2005;353:123-132. doi: 10.1056/NEJMoa050753.

[18] Leoni S, Piscaglia F, Golfieri R, Camaggi V, Vidili G, Pini P, et al. The impact of vascular and nonvascular findings on the noninvasive diagnosis of small hepatocellular carcinoma based on the EASL and AASLD criteria. Am J Gastroenterol 2010;105:599-609. doi: 10.1038/ajg.2009.654.

[19] Choi JY, Lee JM, Sirlin CB. CT and MR imaging diagnosis and staging of hepatocellular carcinoma: part I. Development, growth, and spread: key pathologic and imaging aspects. Radiology 2014;272:635-654. doi: 10. 1148/radiol.14132361.

[20] Taouli B, Koh DM. Diffusion-weighted MR imaging of the liver. Radiology 2010;254:47-66. doi: 10.1148/radiol.09090021.

[21] Seçil M, Obuz F, Altay C, Gencel O, Iğci E, Sağol O, et al. The role of dynamic subtraction MRI in detection of hepatocellular carcinoma. Diagn Interv Radiol 2008;14:200-204.

[22] Colli A, Fraquelli M, Casazza G, Massironi S, Colucci A, Conte D, et al. Accuracy of ultrasonography, spiral $C T$, magnetic resonance, and alpha-fetoprotein in diagnosing hepatocellular carcinoma: a systematic review. Am J Gastroenterol 2006;101:513-523. doi: 10.1111/j.1572-0241.2006.00467.x.

[23] Lee Y], Lee JM, Lee JS, Lee HY, Park BH, Kim YH, et al. Hepatocellular carcinoma: diagnostic performance of multidetector $\mathrm{CT}$ and MR imaging-a systematic review and meta-analysis. Radiology 2015;275:97-109. doi: 10.1148/radiol.14140690.

[24] Barr DC, Hussain HK. MR imaging in cirrhosis and hepatocellular carcinoma. Magn Reson Imaging Clin N Am 2014;22:315-335. doi: 10.1016/j.mric. 2014.04.006

[25] American College of Radiology. Liver imaging reporting and data system (LI-RADS) v2014. Available from: https://www.acr.org/Clinical-Resources/ Reporting-and-Data-Systems/LI-RADS/LI-RADS-v2014.

[26] Goodwin MD, Dobson JE, Sirlin CB, Lim BG, Stella DL. Diagnostic challenges and pitfalls in MR imaging with hepatocyte-specific contrast agents. Radiographics 2011:31:1547-1568. doi: 10.1148/rg.316115528.

[27] Seale MK, Catalano OA, Saini S, Hahn PF, Sahani DV. Hepatobiliary-specific MR contrast agents: role in imaging the liver and biliary tree. Radiographics 2009;29:1725-1748. doi: 10.1148/rg.296095515.

[28] Yu JS, Kim KW, Kim EK, Lee JT, Yoo HS. Contrast enhancement of small hepatocellular carcinoma: usefulness of three successive early image acquisitions during multiphase dynamic MR imaging. AJR Am J Roentgenol 1999;173:597-604. doi: 10.2214/ajr.173.3.10470886.

[29] Forner A, Vilana R, Ayuso C, Bianchi L, Solé M, Ayuso JR, et al. Diagnosis of hepatic nodules $20 \mathrm{~mm}$ or smaller in cirrhosis: Prospective validation of the noninvasive diagnostic criteria for hepatocellular carcinoma. Hepatology 2008;47:97-104. doi: 10.1002/hep.21966.

[30] Bruix J, Sherman M. Management of hepatocellular carcinoma: an update. Hepatology 2011;53:1020-1022. doi: 10.1002/hep.24199.

[31] Bruix J, Sherman M. Management of hepatocellular carcinoma. Hepatology 2005;42:1208-1236. doi: 10.1002/hep.20933.

[32] Rimola J, Forner A, Tremosini S, Reig M, Vilana R, Bianchi L, et al. Noninvasive diagnosis of hepatocellular carcinoma $\leq 2 \mathrm{~cm}$ in cirrhosis. Diagnostic accuracy assessing fat, capsule and signal intensity at dynamic MRI. Hepatol 2012;56:1317-1323. doi: 10.1016/j.jhep.2012.01.004.

[33] Hennedige T, Venkatesh SK. Imaging of hepatocellular carcinoma: diagnosis, staging and treatment monitoring. Cancer Imaging 2013;12:530-547. doi: $10.1102 / 1470-7330.2012 .0044$.

[34] Shah ZK, McKernan MG, Hahn PF, Sahani DV. Enhancing and expansile portal vein thrombosis: value in the diagnosis of hepatocellular carcinoma in patients with multiple hepatic lesions. AJR Am J Roentgenol 2007;188: 1320-1323. doi: 10.2214/AJR.06.0134.

[35] Friedrich-Rust M, Klopffleisch T, Nierhoff J, Herrmann E, Vermehren J, Schneider MD, et al. Contrast-Enhanced Ultrasound for the differentiation of benign and malignant focal liver lesions: a meta-analysis. Liver Int 2013; 33:739-755. doi: 10.1111/liv.12115.
[36] Claudon M, Dietrich CF, Choi BI, Cosgrove DO, Kudo M, Nolsøe CP, et al. Guidelines and good clinical practice recommendations for Contrast Enhanced Ultrasound (CEUS) in the liver - update 2012: A WFUMB-EFSUMB initiative in cooperation with representatives of AFSUMB, AIUM, ASUM, FLAUS and ICUS. Ultrasound Med Biol 2013;39:187-210. doi: 10.1016/j.ultrasmedbio.2012. 09.002.

[37] Park JW, Kim JH, Kim SK, Kang KW, Park KW, Choi JI, et al. A prospective evaluation of $18 \mathrm{~F}-\mathrm{FDG}$ and $11 \mathrm{C}$-acetate PET/CT for detection of primary and metastatic hepatocellular carcinoma. J Nucl Med 2008;49:1912-1921. doi: 10.2967/jnumed.108.055087.

[38] Institute of Medicine. 1999. Organ procurement and transplantation: assessing current policies and the potential impact of the DHHS final rule. Washington, DC: The National Academies Press. doi: 10.17226/9628.

[39] Wald C, Russo MW, Heimbach JK, Hussain HK, Pomfret EA, Bruix J. New OPTN/UNOS policy for liver transplant allocation: standardization of liver imaging, diagnosis, classification, and reporting of hepatocellular carcinoma. Radiology 2013;266:376-382. doi: 10.1148/radiol.12121698.

[40] American College of Radiology. CEUS LI-RADS 2016. Available from: https://www.acr.org/-/media/ACR/Files/RADS/LI-RADS/CEUS-LIRADS_ V3.pdf?la $=$ en

[41] Kee KM, Wang JH, Lee CM, Chen CL, Changchien CS, Hu TH, et al. Validation of clinical AJCC/UICC TNM staging system for hepatocellular carcinoma: analysis of 5,613 cases from a medical center in southern Taiwan. Int J Cancer 2007;120:2650-2655. doi: 10.1002/ijc.22616.

[42] Edge SB, Compton CC. The American Joint Committee on Cancer: the 7th edition of the AJCC cancer staging manual and the future of TNM. Ann Surg Oncol 2010;17:1471-1474. doi: 10.1245/s10434-010-0985-4.

[43] Lu W, Dong J, Huang Z, Guo D, Liu Y, Shi S. Comparison of four current staging systems for Chinese patients with hepatocellular carcinoma undergoing curative resection: Okuda, CLIP, TNM and CUPI. J Gastroenterol Hepatol 2008;23:1874-1878. doi: 10.1111/j.1440-1746.2008.05527.x.

[44] Maida M, Orlando E, Cammà C, Cabibbo G. Staging systems of hepatocellular carcinoma: a review of literature. World J Gastroenterol 2014;20: 4141-4150. doi: 10.3748/wjg.v20.i15.4141.

[45] Okuda K, Obata H, Nakajima Y, Ohtsuki T, Okazaki N, Ohnishi K. Prognosis of primary hepatocellular carcinoma. Hepatology 1984;4:3S-6S. doi: 10. 1002/hep.1840040703.

[46] Addissie BD, Roberts LR. Classification and staging of hepatocellular carcinoma: an aid to clinical decision-making. Clin Liver Dis 2015;19:277-294. doi: 10.1016/j.cld.2015.01.011.

[47] A new prognostic system for hepatocellular carcinoma: a retrospective study of 435 patients: the Cancer of the Liver Italian Program (CLIP) investigators. Hepatology 1998;28:751-755. doi: 10.1002/hep.510280322.

[48] Prospective validation of the CLIP score: a new prognostic system for patients with cirrhosis and hepatocellular carcinoma. The Cancer of the Liver Italian Program (CLIP) Investigators. Hepatology 2000;31:840-845. doi: $10.1053 /$ he.2000.5628

[49] Marrero JA, Fontana RJ, Barrat A, Askari F, Conjeevaram HS, Su GL, et al. Prognosis of hepatocellular carcinoma: comparison of 7 staging systems in an American cohort. Hepatology 2005;41:707-716. doi: 10.1002/hep.20636.

[50] Llovet JM, Brú C, Bruix J. Prognosis of hepatocellular carcinoma: the BCLC staging classification. Semin Liver Dis 1999;19:329-338. doi: 10.1055/s2007-1007122.

[51] Guglielmi A, Ruzzenente A, Pachera S, Valdegamberi A, Sandri M, D'Onofrio $M$, et al. Comparison of seven staging systems in cirrhotic patients with hepatocellular carcinoma in a cohort of patients who underwent radiofrequency ablation with complete response. Am J Gastroenterol 2008;103: 597-604. doi: 10.1111/j.1572-0241.2007.01604.x.

[52] Cillo U, Bassanello M, Vitale A, Grigoletto FA, Burra P, Fagiuoli S, et al. The critical issue of hepatocellular carcinoma prognostic classification: which is the best tool available? J Hepatol 2004;40:124-131. doi: 10.1016/j.jhep. 2003.09.027.

[53] Bruix J, Sherman M, Llovet JM, Beaugrand M, Lencioni R, Burroughs AK, et al. Clinical management of hepatocellular carcinoma. Conclusions of the Barcelona-2000 EASL conference. European Association for the Study of the Liver. J Hepatol 2001;35:421-430.. doi: 10.1016/S0168-8278(01)00130-1

[54] Yau T, Tang VY, Yao TJ, Fan ST, Lo CM, Poon RT. Development of Hong Kong Liver Cancer staging system with treatment stratification for patients with hepatocellular carcinoma. Gastroenterology 2014;146:1691-1700.e3. doi: 10.1053/j.gastro.2014.02.032

[55] Kinoshita A, Onoda H, Fushiya N, Koike K, Nishino H, Tajiri H. Staging systems for hepatocellular carcinoma: Current status and future perspectives. World J Hepatol 2015;7:406-424. doi: 10.4254/wjh.v7.i3.406.

[56] Cillo U, Vitale A, Grigoletto F, Farinati F, Brolese A, Zanus G, et al. Prospective validation of the Barcelona Clinic Liver Cancer staging system. J Hepatol 2006;44:723-731. doi: 10.1016/j.jhep.2005.12.015.

[57] Wang JH, Changchien CS, Hu TH, Lee CM, Kee KM, Lin CY, et al. The efficacy of treatment schedules according to Barcelona Clinic Liver Cancer staging for hepatocellular carcinoma - Survival analysis of 3892 patients. Eur J Cancer 2008;44:1000-1006. doi: 10.1016/j.ejca.2008.02.018. 
[58] Marrero JA, Kudo M, Bronowicki JP. The challenge of prognosis and staging for hepatocellular carcinoma. Oncologist 2010;15 Suppl 4:23-33. doi: 10 . 1634/theoncologist.2010-S4-23.

[59] Meier V, Ramadori G. Clinical staging of hepatocellular carcinoma. Dig Dis 2009;27:131-141. doi: 10.1159/000218345.

[60] Dhir M, Melin AA, Douaiher J, Lin C, Zhen WK, Hussain SM, et al. A review and update of treatment options and controversies in the management of hepatocellular carcinoma. Ann Surg 2016;263:1112-1125. doi: 10.1097/ SLA. 0000000000001556.

[61] Mazzaferro V, Bhoori S, Sposito C, Bongini M, Langer M, Miceli R, et al. Milan criteria in liver transplantation for hepatocellular carcinoma: an evidencebased analysis of 15 years of experience. Liver Transpl 2011;17:S44-S57. doi: $10.1002 /$ lt.22365.

[62] Karakayali H, Moray G, Sozen H, Dalgic A, Emiroglu R, Haberal M. Expanded criteria for liver transplantation in patients with hepatocellular carcinoma. Transplant Proc 2006; 38:575-578. doi: 10.1016/j.transproceed.2006.01.010.

[63] Llovet JM, Bruix J. Systematic review of randomized trials for unresectable hepatocellular carcinoma: Chemoembolization improves survival. Hepatology 2003;37:429-442. doi: 10.1053/jhep.2003.50047.

[64] Kumar Y, Sharma P, Bhatt N, Hooda K. Transarterial therapies for hepatocellular carcinoma: a comprehensive review with current updates and future directions. Asian Pac J Cancer Prev 2016;17:473-478. doi: 10. 7314/APJCP.2016.17.2.473.

[65] Salem R, Lewandowski RJ. Chemoembolization and radioembolization for hepatocellular carcinoma. Clin Gastroenterol Hepatol 2013;11:604-611. doi: $10.1016 / j . c g h .2012 .12 .039$.

[66] Lammer J, Malagari K, Vogl T, Pilleul F, Denys A, Watkinson A, et al. Prospective randomized study of doxorubicin-eluting-bead embolization in the treatment of hepatocellular carcinoma: results of the PRECISION V study. Cardiovasc Intervent Radiol 2010;33:41-52. doi: 10.1007/s00270-009-9711-7.

[67] Maluccio M, Covey AM, Gandhi R, Gonen M, Getrajdman GI, Brody LA, et al. Comparison of survival rates after bland arterial embolization and ablation versus surgical resection for treating solitary hepatocellular carcinoma up to $7 \mathrm{~cm}$. J Vasc Interv Radiol 2005;16:955-961. doi: 10.1097/01.RVI. 0000161377.33557 .20

[68] Covey AM, Maluccio MA, Schubert J, BenPorat L, Brody LA, Sofocleous CT, et al. Particle embolization of recurrent hepatocellular carcinoma after hepatectomy. Cancer 2006;106:2181-2189. doi: 10.1002/cncr.21883.

[69] Lencioni R. Loco-regional treatment of hepatocellular carcinoma. Hepatology 2010;52:762-773. doi: 10.1002/hep.23725.

[70] Kulik LM, Carr BI, Mulcahy MF, Lewandowski RJ, Atassi B, Ryu RK, et al. Safety and efficacy of 90Y radiotherapy for hepatocellular carcinoma with and without portal vein thrombosis. Hepatology 2008;47:71-81. doi: 10 . 1002/hep. 21980.

[71] Salem R, Gordon AC, Mouli S, Hickey R, Kallini J, Gabr A, et al. Y90 radioembolization significantly prolongs time to progression compared with chemoembolization in patients with hepatocellular carcinoma. Gastroenterology 2016;151:1155-1163.e2. doi: 10.1053/j.gastro.2016.08.029.

[72] Llovet JM, Ricci S, Mazzaferro V, Hilgard P, Gane E, Blanc JF, et al. Sorafenib in advanced hepatocellular carcinoma. N Engl J Med 2008;359:378-390. doi: 10.1056/NEJMoa0708857.

[73] Kalva SP, Pectasides M, Liu R, Rachamreddy N, Surakanti S, Yeddula K, et al. Safety and effectiveness of chemoembolization with drug-eluting beads for advanced-stage hepatocellular carcinoma. Cardiovasc Intervent Radiol 2014;37:381-387. doi: 10.1007/s00270-013-0654-7.

[74] Forner A, Ayuso C, Varela M, Rimola J, Hessheimer AJ, de Lope CR, et al. Evaluation of tumor response after locoregional therapies in hepatocellular carcinoma: are response evaluation criteria in solid tumors reliable? Cancer 2009;115:616-623. doi: 10.1002/cncr.24050.

[75] Lo CM, Ngan H, Tso WK, Liu CL, Lam CM, Poon RT, et al. Randomized controlled trial of transarterial lipiodol chemoembolization for unresectable hepatocellular carcinoma. Hepatology 2002;35:1164-1171. doi: 10.1053/ jhep.2002.33156.

[76] Hudes G, Carducci M, Tomczak P, Dutcher J, Figlin R, Kapoor A, et al. Temsirolimus, interferon alfa, or both for advanced renal-cell carcinoma. $\mathrm{N}$ Engl J Med 2007;356:2271-2281. doi: 10.1056/NEJMoa066838.

[77] Lencioni R, Llovet JM. Modified RECIST (mRECIST) assessment for hepatocellular carcinoma. Semin Liver Dis 2010;30:52-60. doi: 10.1055/s-00301247132.

[78] Shim JH, Lee HC, Kim SO, Shin YM, Kim KM, Lim YS, et al. Which response criteria best help predict survival of patients with hepatocellular carcinoma following chemoembolization? A validation study of old and new models. Radiology 2012;262:708-718. doi: 10.1148/radiol.11110282.

[79] Kim BK, Kim SU, Kim KA, Chung YE, Kim MJ, Park MS, et al. Complete response at first chemoembolization is still the most robust predictor for favorable outcome in hepatocellular carcinoma. J Hepatol 2015;62:13041310. doi: 10.1016/j.jhep.2015.01.022.

[80] Prajapati HJ, Spivey JR, Hanish SI, El-Rayes BF, Kauh JS, Chen Z, et al. mRECIST and EASL responses at early time point by contrast-enhanced dynamic MRI predict survival in patients with unresectable hepatocellular carcinoma $(\mathrm{HCC})$ treated by doxorubicin drug-eluting beads transarterial chemoembolization (DEB TACE). Ann Oncol 2013;24:965-973. doi: 10. 1093/annonc/mds605.

[81] Jung ES, Kim JH, Yoon EL, Lee HJ, Lee SJ, Suh SJ, et al. Comparison of the methods for tumor response assessment in patients with hepatocellular carcinoma undergoing transarterial chemoembolization. J Hepatol 2013; 58:1181-1187. doi: 10.1016/j.jhep.2013.01.039.

[82] Gunn AJ, Sheth RA, Luber B, Huynh MH, Rachamreddy NR, Kalva SP. Predicting outcomes after chemo-embolization in patients with advancedstage hepatocellular carcinoma: an evaluation of different radiologic response criteria. Cardiovasc Intervent Radiol 2017;40:61-68. doi: 10. 1007/s00270-016-1451-x.

[83] Galizia MS, Töre HG, Chalian H, McCarthy R, Salem R, Yaghmai V. MDCT necrosis quantification in the assessment of hepatocellular carcinoma response to yttrium 90 radioembolization therapy: comparison of twodimensional and volumetric techniques. Acad Radiol 2012;19:48-54. doi: 10.1016/j.acra.2011.09.005.

[84] Fleckenstein FN, Schernthaner RE, Duran R, Sohn JH, Sahu S, Zhao Y, et al. 3D Quantitative tumour burden analysis in patients with hepatocellular carcinoma before TACE: comparing single-lesion vs. multi-lesion imaging biomarkers as predictors of patient survival. Eur Radiol 2016;26:3243-3252. doi: 10.1007/s00330-015-4168-3.

[85] Lin M, Pellerin O, Bhagat N, Rao PP, Loffroy R, Ardon R, et al. Quantitative and volumetric European Association for the Study of the Liver and Response Evaluation Criteria in Solid Tumors measurements: feasibility of a semiautomated software method to assess tumor response after transcatheter arterial chemoembolization. J Vasc Interv Radiol 2012;23:16291637. doi: $10.1016 /$ j.jvir.2012.08.028.

[86] Chapiro J, Wood LD, Lin M, Duran R, Cornish T, Lesage D, et al. Radiologicpathologic analysis of contrast-enhanced and diffusion-weighted MR imaging in patients with HCC after TACE: diagnostic accuracy of 3D quantitative image analysis. Radiology 2014;273:746-758. doi: 10.1148/radiol.14140033.

[87] Zhao B, James LP, Moskowitz CS, Guo P, Ginsberg MS, Lefkowitz RA, et al. Evaluating variability in tumor measurements from same-day repeat CT scans of patients with non-small cell lung cancer. Radiology 2009;252: 263-272. doi: 10.1148/radiol.2522081593.

[88] Baghi M, Bisdas S, Engels K, Yousefi M, Wagenblast J, Hambek M, et al. Prognostic relevance of volumetric analysis in tumour specimens of hypopharyngeal cancer. Clin Otolaryngol 2007;32:372-377. doi: 10.1111/j. 1749-4486.2007.01531.x.

[89] Dai X, Schlemmer HP, Schmidt B, Höh K, Xu K, Ganten TM, et al. Quantitative therapy response assessment by volumetric iodine-uptake measurement: initial experience in patients with advanced hepatocellular carcinoma treated with sorafenib. Eur J Radiol 2013;82:327-334. doi: 10.1016/j. ejrad.2012.11.013.

[90] Apfaltrer P, Meyer M, Meier C, Henzler T, Barraza JM Jr, Dinter DJ, et al. Contrast-enhanced dual-energy CT of gastrointestinal stromal tumors: is iodine-related attenuation a potential indicator of tumor response? Invest Radiol 2012;47:65-70. doi: 10.1097/RLI.0b013e31823003d2.

[91] Thaiss WM, Haberland U, Kaufmann S, Spira D, Thomas C, Nikolaou K, et al. Iodine concentration as a perfusion surrogate marker in oncology: Further elucidation of the underlying mechanisms using Volume Perfusion CT with 80 kVp. Eur Radiol 2016;26:2929-2936. doi: 10.1007/s00330-015-4154-9.

[92] Altenbernd J, Wetter A, Forsting M, Umutlu L. Treatment response after radioembolisation in patients with hepatocellular carcinoma-An evaluation with dual energy computed-tomography. Eur J Radiol Open 2016;3:230235. doi: 10.1016/j.ejro.2016.08.002.

[93] Miyayama S, Yamashiro M, Okuda M, Yoshie Y, Sugimori N, Igarashi S, et al. Usefulness of cone-beam computed tomography during ultraselective transcatheter arterial chemoembolization for small hepatocellular carcinomas that cannot be demonstrated on angiography. Cardiovasc Intervent Radiol 2009;32:255-264. doi: 10.1007/s00270-008-9468-4.

[94] Tognolini A, Louie JD, Hwang GL, Hofmann LV, Sze DY, Kothary N. Utility of $\mathrm{C}$-arm CT in patients with hepatocellular carcinoma undergoing transhepatic arterial chemoembolization. J Vasc Interv Radiol 2010;21:339-347. doi: $10.1016 /$ j.jvir.2009.11.007.

[95] Iwazawa J, Ohue S, Mitani T, Abe H, Hashimoto N, Hamuro M, et al. Identifying feeding arteries during TACE of hepatic tumors: comparison of C-arm CT and digital subtraction angiography. AJR Am J Roentgenol 2009;192: 1057-1063. doi: 10.2214/AJR.08.1285.

[96] Iwazawa J, Ohue S, Hashimoto N, Muramoto O, Mitani T. Survival after Carm CT-assisted chemoembolization of unresectable hepatocellular carcinoma. Eur J Radiol 2012;81:3985-3992. doi: 10.1016/j.ejrad.2012.08.012.

[97] Monsky WL, Kim I, Loh S, Li CS, Greasby TA, Deutsch LS, et al. Semiautomated segmentation for volumetric analysis of intratumoral ethiodol uptake and subsequent tumor necrosis after chemoembolization. AJR Am J Roentgenol 2010;195:1220-1230. doi: 10.2214/AJR.09.3964.

[98] Takayasu K, Muramatsu Y, Maeda T, Iwata R, Furukawa H, Muramatsu Y, et al. Targeted transarterial oily chemoembolization for small foci of hepatocellular carcinoma using a unified helical CT and angiography system: analysis of 
factors affecting local recurrence and survival rates. AJR Am J Roentgenol 2001;176:681-688. doi: 10.2214/ajr.176.3.1760681

[99] Chen R, Geschwind JF, Wang Z, Tacher V, Lin M. Quantitative assessment of lipiodol deposition after chemoembolization: comparison between conebeam CT and multidetector CT. J Vasc Interv Radiol 2013;24:1837-1844. doi: $10.1016 / j$.jvir.2013.08.017.

[100] Hu J, Maybody M, Cao G, Wang X, Chen H, Zhu X, et al. Lipiodol retention pattern assessed by cone beam computed tomography during conventional transarterial chemoembolization of hepatocellular carcinoma: accuracy and correlation with response. Cancer Imaging 2016;16:32. doi: 10.1186/ s40644-016-0090-4.

[101] Loffroy $R$, Lin M, Yenokyan G, Rao PP, Bhagat $N$, Noordhoek $N$, et al. Intraprocedural C-arm dual-phase cone-beam CT: can it be used to predict shortterm response to TACE with drug-eluting beads in patients with hepatocellular carcinoma? Radiology 2013;266:636-648. doi: 10.1148/radiol.12112316.

[102] Müller K, Datta S, Gehrisch S, Ahmad M, Mohammed MA, Rosenberg J, et al. The role of dual-phase cone-beam CT in predicting short-term response after transarterial chemoembolization for hepatocellular carcinoma. J Vasc Interv Radiol 2017;28:238-245. doi: 10.1016/j.jvir.2016.09.019.

[103] Frampas E, Lassau N, Zappa M, Vullierme MP, Koscielny S, Vilgrain V. Advanced Hepatocellular Carcinoma: early evaluation of response to targeted therapy and prognostic value of Perfusion CT and Dynamic Contrast Enhanced-Ultrasound. Preliminary results. Eur J Radiol 2013;82:e205-e211. doi: $10.1016 /$ j.ejrad.2012.12.004

[104] Ippolito D, Bonaffini PA, Ratti L, Antolini L, Corso R, Fazio F, et al. Hepatocellular carcinoma treated with transarterial chemoembolization: dynamic perfusion-CT in the assessment of residual tumor. World J Gastroenterol 2010;16:5993-6000.

[105] Su TH, He W, Jin L, Chen G, Xiao GW. Early response of hepatocellula carcinoma to chemoembolization: volume computed tomography liver perfusion imaging as a short-term response predictor. J Comput Assist Tomogr 2017;41:315-320. doi: 10.1097/RCT.0000000000000511.

[106] Tamandl D, Waneck F, Sieghart W, Unterhumer S, Kölblinger C, Baltzer P, et al. Early response evaluation using CT-perfusion one day after transarterial chemoembolization for HCC predicts treatment response and long-term disease control. Eur J Radiol 2017;90:73-80. doi: 10.1016/j. ejrad.2017.02.032.

[107] Reiner CS, Gordic S, Puippe G, Morsbach F, Wurnig M, Schaefer N, et al. Histogram analysis of CT perfusion of hepatocellular carcinoma for predicting response to transarterial radioembolization: value of tumor heterogeneity assessment. Cardiovasc Intervent Radiol 2016;39:400-408. doi: 10 1007/s00270-015-1185-1. 